Conversion of Parameters Among Variants of Scatchard's

Neutral-Electrolyte Model for Electrolyte Mixtures that Have Different Numbers of Mixing Terms

J. A. Rard, A. M. Wijesinghe

February 14, 2008

Journal of Solution Chemistry 
This document was prepared as an account of work sponsored by an agency of the United States government. Neither the United States government nor Lawrence Livermore National Security, LLC, nor any of their employees makes any warranty, expressed or implied, or assumes any legal liability or responsibility for the accuracy, completeness, or usefulness of any information, apparatus, product, or process disclosed, or represents that its use would not infringe privately owned rights. Reference herein to any specific commercial product, process, or service by trade name, trademark, manufacturer, or otherwise does not necessarily constitute or imply its endorsement, recommendation, or favoring by the United States government or Lawrence Livermore National Security, LLC. The views and opinions of authors expressed herein do not necessarily state or reflect those of the United States government or Lawrence Livermore National Security, LLC, and shall not be used for advertising or product endorsement purposes. 


\title{
Conversion of Parameters Among Variants of Scatchard's Neutral- Electrolyte Model for Electrolyte Mixtures that Have Different Numbers of Mixing Terms
}

\author{
Joseph A. Rard · Ananda M. Wijesinghe
}

\begin{abstract}
Various model equations are available for representing the excess Gibbs energy properties (osmotic and activity coefficients) of aqueous and other liquid mixedelectrolyte solutions. Scatchard's neutral-electrolyte model is among the simplest of these equations for ternary systems and contains terms that represent both symmetrical and asymmetric deviations from ideal mixing behavior when two single-electrolyte solutions are mixed in different proportions at constant ionic strengths. The usual form of this model allows from zero to six mixing parameters. In this report we present an analytical method for transforming the mixing parameters of neutral-electrolyte-type models with larger numbers of mixing parameters directly to those of models with fewer mixing parameters, without recourse to the source data used for evaluation of the original model parameters. The equations for this parameter conversion are based on an extension to ternary systems of the methodology of Rard and Wijesinghe [J. Chem. Thermodyn. 35,
\end{abstract} 439-473 (2003)] and Wijesinghe and Rard [J. Chem. Thermodyn. 37, 1196-1218 (2005)] that was applied by them to binary systems. It was found that the use of this approach with a constant ionic-strength cutoff of $I \leq 6.2 \mathrm{~mol} \cdot \mathrm{kg}^{-1}$ (the $\mathrm{NaCl}$ solubility limit) yielded parameters for the $\mathrm{NaCl}+\mathrm{SrCl}_{2}+\mathrm{H}_{2} \mathrm{O}$ and $\mathrm{NaCl}+\mathrm{MgCl}_{2}+\mathrm{H}_{2} \mathrm{O}$ systems that predicted osmotic coefficients $\phi$ in excellent agreement with those calculated using the same sets of parameters whose values were evaluated directly from the source data by least-squares, with root mean square differences of $\operatorname{RMSE}(\phi)=0.00006$ to 0.00062 for the first system and $\operatorname{RMSE}(\phi)=0.00014$ to 0.00042 for the second. If, however, the directly evaluated parameters were based on experimental data where the ionic strength cutoff varied with the ionic-strength fraction, i.e. because they were constrained by isopiestic ionic strengths $\left(\mathrm{MgCl}_{2}+\mathrm{MgSO}_{4}+\mathrm{H}_{2} \mathrm{O}\right)$ or solubility / oversaturation ionic strengths $\left(\mathrm{NaCl}+\mathrm{SrCl}_{2}+\right.$ $\mathrm{H}_{2} \mathrm{O}$ and $\mathrm{NaCl}+\mathrm{MgCl}_{2}+\mathrm{H}_{2} \mathrm{O}$ ), then parameters converted by this approach assuming a 
constant ionic-strength cutoff yield $\operatorname{RMSE}(\phi)$ differences about an order of magnitude larger than the previous case. This indicates that for an accurate conversion of model parameters when the source model is constrained with variable ionic strength cutoffs, an extension of the parameter conversion method described herein will be required. However, when the source model parameters are evaluated at a constant ionic strength cuttoff, such as when source isopiestic data are constrained to ionic strengths at or below the solubility limit of the less soluble component, or are Emf measurements that are commonly made at constant ionic strengths, then our method yields accurate converted models.

Keywords Ternary solutions $\cdot$ Mixed electrolytes $\cdot$ Osmotic Coefficients $\cdot$ Aqueous solutions $\cdot$ Scatchard's neutral-electrolyte model

\section{J. A. Rard (retired) $\ \cdot$ A. M. Wijesinghe}

Chemistry, Materials, Earth and Life Sciences Directorate, Lawrence Livermore National Laboratory, Livermore, CA 94550, USA

e-mail: solution_chemistry2@comcast.net

\section{Introduction}

Natural waters are aqueous mixtures of electrolytes that in some cases are very concentrated (brines), whereas biofluids such as intra- and intercellular liquids contain mixtures of electrolytes in addition to their organic and biological components. Aqueous solutions are also used as a medium for purification of electrolytes by recrystallization, ion exchange, liquid-liquid extraction, etc., and for applications such as growing of highquality crystals needed for single crystal X-ray structural determinations.

The large number of possible aqueous electrolyte mixtures, and the widespread interest in their thermodynamic properties, has generated much interest in representing, correlating, and estimating their thermodynamic properties. One of the earliest equations for representing the variation of activity coefficients with solution composition, which since then has been commonly referred to as "Harned's rule", was presented by Harned and Owen [1]. They observed that the logarithm of the activity coefficient of one solute 
in an aqueous common-ion two-electrolyte mixture at lower concentrations was a linear function of the molality (or molality-based ionic strength $I$ ) of the other solute when the total molality (or ionic strength) was kept constant. When the measurements extend to moderate ionic strengths or when complex formation occurs, an additional quadratic term in the molalities (or ionic strength) is generally needed to reliably represent the data. Robinson and Stokes [2] have also discussed this approach and summarized some of the systems modeled with this equation. However, because this approach is limited to four parameters (two mixing parameters with the other two parameters being the trace activity coefficients of each solute in a solution of the other component) for the original form of Harned's rule, it is generally not able to represent activity data to their full experimental precision at high ionic strengths. Furthermore, each set of Harned coefficients pertains to a single constant ionic strength or constant total molality, and an additional set is needed each time the total concentration is changed.

Scatchard's neutral-electrolyte model [3] allows up to five mixing parameters in terms that describe mixing effects that are both symmetric and asymmetric in the ionicstrength fractions of the two electrolytes. This model is capable of accurately representing osmotic and activity coefficients of mixtures with, or without, a common ion to high ionic strengths. Rush [4] has reported mixing parameters for this model for many aqueous electrolyte mixtures at $298.15 \mathrm{~K}$.

Friedman's [5] use of the cluster-expansion method produced an expression for the Gibbs energy of mixing per kilogram of the solvent for common-ion mixtures that contains an arbitrary number of terms of the form $\operatorname{RTI}^{2} y(1-y) g_{n}(2 y-1)^{n}$, where $y$ is the ionic-strength fraction of one of the electrolytes, $R$ is the universal gas constant, $T$ is the absolute temperature, and $n$ is a positive integer that ranges from zero to infinity. Wigent and Leifer [6] and Leifer and Wigent [7] give equations relating Friedman's $g_{n}$ mixing coefficients to those of Scatchard's neutral-electrolyte model and generalized the mixing terms of the neutral-electrolyte model to include higher-order interactions [7]. Blandamer et al. [8] have summarized some additional mixing equations with an emphasis on mixing relations for water activities.

Pitzer's ion-interaction model has been used extensively in the thermodynamic modeling of aqueous electrolyte mixtures and this model has been incorporated into 
several geochemical modeling codes. Pitzer's book chapter [9] describes this model in detail, provides numerous references, and gives extensive tables of model parameters. For common-ion ternary electrolyte solutions this model allows two mixing parameters. Clegg and Whitfield [10] have summarized numerous studies in the literature in which Pitzer's model has been used to represent the thermodynamic activities of concentrated electrolyte mixtures and also describe alternative thermodynamic models based on the assumed presence of ion pairing.

Although Scatchard chose a particular extended Debye-Hückel model function to represent the osmotic and activity coefficients of the single electrolytes when he formulated the neutral-electrolyte model [3] (see below, Eq. 2)) there is nothing inherent in his model that limits it to that choice of functional form for the binary solutions. In several studies $[11,12]$, Pitzer's ion-interaction equations for the single electrolyte solutions have been combined with mixing terms from Scatchard's neutral-electrolyte model to yield very accurate representations of their isopiestic data for common-ion aqueous electrolyte mixtures. This hybrid model gave significantly more accurate fits than the corresponding ones with Pitzer's two-parameter mixing function.

Because the neutral-electrolyte model uses a very flexible combination of mixing terms with five [3] or more [7] mixing parameters, it is capable of accurately representing thermodynamic activity data for ternary solutions to very high ionic strengths. However, although five or six of these mixing parameters may be required for some electrolyte mixtures, in other cases such as when the ionic strength range is more limited or when the electrolytes are common-ion mixtures of the same charge type, fewer parameters may be needed. Some mixing parameter values may be small and, although including them may slightly improve the representation of the source data, their presence may or may not be significant. This is especially true for terms that represent asymmetric mixing effects, because they are generally much smaller than those for symmetric mixing effects. Consequently, it is desirable to compare fits with different numbers of mixing parameters in order to select the optimal set. However, the largest tabulation of neutral-electrolyte mixing parameters [4] only gives those for the author's preferred combination of mixing parameters, so it is not possible to directly test whether other combinations of model 
parameters would have yielded better or comparable representations without re-creating the original data base.

Rard and Wijesinghe [13] and Wijesinghe and Rard [14] described a general methodology whereby the parameters of a thermodynamic model can be directly transformed into a variant of that model with a reduced number of model parameters. They applied this approach to the specific case of transforming the parameters of extended forms of Pitzer's ion-interaction model for single-electrolyte solutions to those of the standard 3-parameter form. This approach has the advantage that the optimized parameters for the standard model are obtained from those of the extended model without needing to regenerate the database used to evaluate the original parameters. In the present report we extend their methodology to ternary mixed-electrolyte solutions and present analytical equations for transforming the parameters of Scatchard's neutral-electrolyte model [3] to variants of the same model with fewer mixing parameters. This provides a simple method to test whether different combinations of fewer model parameters can adequately represent the same activity data.

\section{Scatchard's Neutral-Electrolyte Model Equation}

Scatchard's neutral-electrolyte model equation for the osmotic coefficient of a mixture of two electrolytes [3], with additional terms as described by Leifer and Wigent [7] for quadruplet and higher-order ionic interactions, can be written in the form:

$$
\begin{aligned}
\frac{\left(\sum_{i=1}^{2} v_{i} m_{i}\right) \phi^{\mathrm{s}}}{I} & =\frac{\sum_{i=1}^{2} v_{i} m_{i} \phi_{i}^{*}}{I}+y_{1} y_{2} \sum_{l=0}^{L} \sum_{m=l+1}^{M}\left(y_{1}-y_{2}\right)^{l} b_{l m} I^{m} \\
& =\left(\frac{v_{1} m_{1}}{I}\right) \phi_{1}^{*}+\left(\frac{v_{2} m_{2}}{I}\right) \phi_{2}^{*}+y_{1} y_{2}\left(b_{01} I+b_{02} I^{2}+b_{03} I^{3}\right) \\
& +y_{1} y_{2}\left(y_{1}-y_{2}\right)\left(b_{12} I^{2}+b_{13} I^{3}\right)+y_{1} y_{2}\left(y_{1}-y_{2}\right)^{2} b_{23} I^{3}
\end{aligned}
$$

where $\phi^{\mathrm{S}}$ is the osmotic coefficient of the mixed-electrolyte solution as expressed by Scatchard's model, $m_{i}$ is the molality and $v_{i}$ the number of ions formed by dissociation of one molecule of the $i^{\text {th }}$ electrolyte, subscripts ${ }_{1}$ and ${ }_{2}$ denote the two electrolytes, $\phi_{1}^{*}$ and $\phi_{2}^{*}$ are the osmotic coefficients of the two single-electrolyte solutions evaluated at the 
total ionic strength of the solution $I, y_{1}$ is the ionic-strength fraction of electrolyte 1 and $y_{2}$ $=1-y_{1}$ the ionic-strength fraction of electrolyte 2 , and the $b_{l m}$ are empirical mixing parameters. The highest-order ionic interactions considered in this report are defined by $L$ $=2$ and $M=3$ but, in principle, they can be of even higher order subject to the restriction that $M=L+1$. The number of $b_{l m}$ parameters in this model is equal to $N=\{(L+1)(2 M-$ $L) / 2$ \}. When the interaction terms are written out explicitly in Eq. 1 (and Eq. 5 below), they are only given to the quadruplet ionic interaction level because we are not aware of any systems for which additional terms are needed. The first two terms on the right-handside of the second line of Eq. 1 represent ideal mixing at constant ionic strength according to this model, i.e., when all of the $b_{l m}=0$. The $y_{1} y_{2}\left(b_{01} I+b_{02} I^{2}+b_{03} I^{3}\right)$ term represents non-ideal mixing effects that are symmetrical in the ionic-strength fractions of the two electrolytes, and the $y_{1} y_{2}\left(y_{1}-y_{2}\right)\left(b_{12} I^{2}+b_{13} I^{3}\right)+y_{1} y_{2}\left(y_{1}-y_{2}\right)^{2} b_{23} I^{3}$ terms represent non-ideal mixing effects that are asymmetrical in the ionic-strength fractions of the two electrolytes.

The equation that was generally used by Scatchard and by Rush [3, 4] to represent the osmotic coefficient of a solution of a single electrolyte $i$ can be re-written in the equivalent form:

$$
\phi_{i}=1-\left(\frac{\left|z_{i c}\right|\left|\mathrm{Z}_{i \mathrm{a}}\right| A_{\gamma}}{\left(B_{i}\right)^{3} I}\right)\left[\left(1+B_{i} I^{1 / 2}\right)-\left(\frac{1}{1+B_{i} I^{1 / 2}}\right)-2 \ln \left(1+B_{i} I^{1 / 2}\right)\right]+a^{(i 1)} I+a^{(i 2)} I^{2}+a^{(i 3)} I^{3}+\ldots
$$

where $B_{i}$ is related to the ion-size parameter for that electrolyte, $z_{i c}$ is the charge on the cation and $z_{i \mathrm{a}}$ the charge of the anion (with sign), $A_{\gamma}$ is the Debye-Hückel limiting-law slope for $\ln \gamma_{ \pm}$, and $a^{(i j)}$ is the $j$ th empirical fitting parameter for electrolyte $i$. (These authors actually wrote their equations in terms of the $\alpha_{\mathrm{J}}$ function where $\alpha_{\mathrm{J}}=1-\phi$.)

When analyzing isopiestic data for aqueous mixed electrolytes with the neutralelectrolyte equation, Rard and Miller $[15,16]$ used an alternative expression for the osmotic coefficient of a single electrolyte that is based on the Debye-Hückel limiting law. Their binary solution equation can be re-written in the form:

$$
\phi_{i}=1-\left(\frac{\left|z_{i \mathrm{c}}\right|\left|\mathrm{z}_{i \mathrm{a}}\right| A_{\gamma}}{3}\right) I^{1 / 2}+\sum_{j=1}^{n} A_{i j} m^{r_{j}}
$$

where the $A_{i j}$ are empirical parameters. 
Pavićević et al. [11] and Miladinović et al. [12] analyzed isopiestic data for mixed electrolyte solutions with Scatchard's neutral-electrolyte model [3] with the single electrolyte osmotic coefficients being represented by Pitzer's standard ioninteraction model [9] or an extended (Archer-type) [17] ion-interaction model. The extended equation can be written as:

$$
\begin{aligned}
\phi_{i}=1 & -\left|z_{i \mathrm{c}} z_{i \mathrm{a}}\right| A_{\phi}\left(\frac{I^{1 / 2}}{1+b I^{1 / 2}}\right)+\left(\frac{2 v_{i \mathrm{c}} v_{i \mathrm{a}}}{v_{i}}\right) m\left\{\beta_{i \mathrm{c}, i \mathrm{a}}^{(0)}+\beta_{i \mathrm{c}, i \mathrm{a}}^{(1)} \exp \left(-\alpha_{1, i} I^{1 / 2}\right)+\beta_{i \mathrm{c}, i \mathrm{a}}^{(2)} \exp \left(-\alpha_{2, i} I^{1 / 2}\right)\right\} \\
& +\left(\frac{4 v_{i \mathrm{c}}{ }^{2} v_{i \mathrm{a}} z_{i \mathrm{c}}}{v_{i}}\right) m^{2}\left\{C_{i c, i a}^{(0)}+C_{i \mathrm{c}, i \mathrm{a}}^{(1)} \exp \left(-\omega_{1, i} I^{1 / 2}\right)\right\}
\end{aligned}
$$

where $A_{\phi}$ is the Debye-Hückel limiting-law slope for the osmotic coefficient, $v_{i c}$ is the number of cations formed by dissociation of one molecule of electrolyte $i$ and $v_{i \mathrm{a}}$ the corresponding number of anions, and $v_{i}=v_{i c}+v_{i \mathrm{a}}$. Pitzer's standard model can be recovered from this equation by setting $C_{i c, i a}^{(1)}=0$ and multiplying the numerical coefficient of the last term by $\left(v_{i \mathrm{a}} / v_{i c}\right)^{1 / 2} / 2 z_{i c}$.

Pitzer et al. [18] have reported a completely general form of the ion-interaction model that can give very accurate representations of osmotic coefficient data for single electrolyte solutions. Although this generalized equation has yet to be used in combination with Scatchard's neutral-electrolyte model [3], its application should yield very accurate model fits to activity data for mixed-electrolyte solutions. We note in this regard that Wang et al. [19] have evaluated the parameters of this generalized model for 40 aqueous trivalent rare-earth chlorides, perchlorates, and nitrates at $298.15 \mathrm{~K}$ to the highest studied molalities. Thermodynamic equations based on the mole-fraction composition scale [20 - 22] have also been used to represent the osmotic and activity coefficients of very soluble electrolytes, and their single-electrolyte equations could similarly be used in conjunction with the mixing terms of Scatchard's neutral-electrolyte model [3] given above in Eq. 1.

We also note that we have partly changed some notation in some of the above equations from those used in the cited sources, in order to give a more uniform presentation. 
Equation 1, as written above, is a function of several composition variables (the ionic molalities of each constituent electrolyte, the sum of these ionic molalities, and the total ionic strength of the mixture) along with the ionic-strength fractions of both electrolytes in the mixture. To facilitate the analysis in the next section, we now recast the mixing terms of this equation in terms of the ionic-strength fraction of only the first electrolyte:

$$
\begin{aligned}
\frac{\left(\sum_{i=1}^{2} v_{i} m_{i}\right) \phi^{\mathrm{S}}}{I}= & \frac{\sum_{i=1}^{2} v_{i} m_{i} \phi_{i}^{*}}{I}+y_{1}\left(1-y_{1}\right) \sum_{l=0}^{L} \sum_{m=l+1}^{M}\left(2 y_{1}-1\right)^{l} I^{m} b_{l m} \\
& =\left(\frac{v_{1} m_{1}}{I}\right) \phi_{1}^{*}+\left(\frac{v_{2} m_{2}}{I}\right) \phi_{2}^{*}+y_{1}\left(1-y_{1}\right)\left(b_{01} I+b_{02} I^{2}+b_{03} I^{3}\right) \\
& +y_{1}\left(1-y_{1}\right)\left(2 y_{1}-1\right)\left(b_{12} I^{2}+b_{13} I^{3}\right)+y_{1}\left(1-y_{1}\right)\left(2 y_{1}-1\right)^{2} b_{23} I^{3}
\end{aligned}
$$

\section{Parameter Transformation Equations}

Rard and Wijesinghe [13] and Wijesinghe and Rard [14] described a general method by which parameters of a thermodynamic model can be transformed to those of a variant of the same model having fewer adjustable parameters. They applied this method to the specific case of converting the parameters of extended forms of Pitzer's ion-interaction model for single electrolyte solutions, given by Eq. 4 and also for an extension with an additional $C_{i \mathrm{c}, i \mathrm{a}}^{(2)} \exp \left(-\omega_{2, i} I^{1 / 2}\right)$ term, to those of the standard ion-interaction model where $C_{i c, i \mathrm{a}}^{(1)}=0$ and $C_{i \mathrm{c}, i \mathrm{a}}^{(2)}=0$. The resulting conversion equations, although complicated, have analytical solutions.

The starting point of their approach was the adoption of the mean square difference between the two functions for the osmotic coefficient, having known and unknown parameters, as the objective function that was to be minimized over the ionic strength range (and normalized by the maximum ionic strength) of interest:

$$
E_{\phi, I}^{2} \equiv \frac{\int_{I=0}^{I_{\max }}\left(\phi^{\mathrm{P}}-\phi^{\mathrm{EA}}\right)^{2} \mathrm{~d} I}{\int_{I=0}^{I_{\max }} \mathrm{d} I}=\left(\frac{1}{I_{\max }}\right) \int_{I=0}^{I_{\max }}\left(\phi^{\mathrm{P}}-\phi^{\mathrm{EA}}\right)^{2} \mathrm{~d} I
$$


where $\phi^{\mathrm{EA}}$ is the osmotic coefficient as given by the extended ion-interaction model with known parameters, and $\phi^{\mathrm{P}}$ is the osmotic coefficient as given by the standard threeparameter ion-interaction (Pitzer) model whose optimum parameters were to be determined. By setting to zero all of the derivatives of $E_{\phi, I}^{2}$ with respect to each of the parameters of the standard Pitzer model, a set of simultaneous equations, whose solution yields the desired transformation equations, was obtained for the unknown model parameters. The notation $E_{\phi, I}^{2}$ is used because it represents the mean of the square "error" for the derived standard ion-interaction model that results from the use of fewer model parameters, which is in addition to that present in the source model resulting from limitations in the thermodynamic data used for its parameter evaluation.

For a ternary mixed-electrolyte solution containing two solutes, the analog of Eq. 6 for evaluating the mean-square error in the osmotic coefficient requires integration over two composition variables. The analog of Eq. 6 is thus

$$
E_{\phi, I, y}^{2} \equiv \frac{\int_{\mathrm{y}_{1}=0}^{\mathrm{y}_{1}=1 I_{\max }} \int_{I=0}^{\mathrm{y}_{\mathrm{I}_{1}=1 I_{\max }}}\left(\phi^{\mathrm{S}, \mathrm{t}}-\phi^{\mathrm{s}}\right)^{2} \mathrm{~d} I \mathrm{~d} y_{1}}{\int_{\mathrm{y}_{1}=0} \int_{I=0} \mathrm{~d} I \mathrm{~d} y_{1}}
$$

However, after considering the form of Scatchard's neutral electrolyte equation as given by Eq. 5 , an alternate form of the objective function that leads to a relatively simple expression for the evaluation of the model parameters is

$$
E_{f, I, y}^{2} \equiv \frac{\int_{\mathrm{y}_{1}=0}^{\mathrm{y}_{1}=1 I_{\max }} \int_{I=0}\left(\frac{\sum_{i=1}^{i=2} v_{i} m_{i}}{I}\right)^{2}\left(\phi^{\mathrm{S}, \mathrm{t}}-\phi^{\mathrm{S}}\right)^{2} \mathrm{~d} I \mathrm{~d} y_{1}}{\int_{\mathrm{y}_{1}=0}^{\mathrm{y}_{1}=1 I_{\max }} \int_{I=0}^{i=2}\left(\frac{\sum_{i=1} v_{i} m_{i}}{I}\right)^{2} \mathrm{~d} I \mathrm{~d} y_{1}}
$$

where $\phi^{\mathrm{S}}$ is given by Eq. 5 and $\phi^{\mathrm{S}, \mathrm{t}}$ is a truncated form of this equation that contains the same binary solution contributions but has fewer $b_{l m}$ mixing parameters. It should be noted that the source model for $\phi^{\mathrm{S}}$ might not contain all six of the $b_{l m}$ mixing parameters if one or more were set to zero in their original evaluation from the source data. The denominator of Eq. $7 \mathrm{~b}$ was chosen to normalize the model error function so that $E_{f, I, y}^{2}$ corresponds to the mean-square difference function for the osmotic coefficient. The 
mean square error function $E_{f, I, y}^{2}$ was defined for the osmotic coefficient rather that an activity coefficient for one of the electrolytes (or the equivalent excess Gibbs energy) because the primary Gibbs energy data for most electrolytes and mixtures are osmotic coefficient values derived from isopiestic measurements.

We now consider the denominator of Eq. 7b, and will first transform $\left(\frac{\sum_{i=1}^{i=2} v_{i} m_{i}}{I}\right)$ into a function of the integration variables. The ionic strength of electrolytes 1 and 2 in the mixture are given by

$$
\begin{aligned}
& I_{1}=y_{1} I=\left(\frac{1}{2}\right)\left\{m_{1 \mathrm{a}}\left|z_{1 \mathrm{a}}\right|^{2}+m_{1 \mathrm{c}}\left|z_{1 \mathrm{c}}\right|^{2}\right\} \\
& I_{2}=\left(1-y_{1}\right) I=\left(\frac{1}{2}\right)\left\{m_{2 \mathrm{a}}\left|z_{2 \mathrm{a}}\right|^{2}+m_{2 \mathrm{c}}\left|z_{2 \mathrm{c}}\right|^{2}\right\}
\end{aligned}
$$

where $m_{i c}$ and $m_{i a}$ are, respectively, the ionic molalities of cation and anion resulting from the complete dissociation of electrolyte $i$. The condition of electroneutrality for this electrolyte $i$ yields

$$
\begin{aligned}
& \left|z_{i \mathrm{a}}\right|=\frac{m_{i \mathrm{c}}\left|z_{i \mathrm{c}}\right|}{m_{i \mathrm{a}}} \\
& \left|z_{i \mathrm{c}}\right|=\frac{m_{i \mathrm{a}}\left|z_{i \mathrm{a}}\right|}{m_{i \mathrm{c}}}
\end{aligned}
$$

Inserting Eqs. 9a and 9b into Eq. 8 yields

$$
\begin{aligned}
I_{1} & =\left(\frac{1}{2}\right)\left|z_{1 \mathrm{c}} \| z_{1 \mathrm{a}}\right|\left(m_{1 \mathrm{c}}+m_{1 \mathrm{a}}\right) \\
& =\left(\frac{1}{2}\right)\left|z_{1 \mathrm{c}}\right| z_{1 \mathrm{a}} \mid v_{1} m_{1}
\end{aligned}
$$

and for the second electrolyte,

$$
\begin{aligned}
I_{2} & =\left(\frac{1}{2}\right)\left|z_{2 \mathrm{c}} \| z_{2 \mathrm{a}}\right|\left(m_{2 \mathrm{c}}+m_{2 \mathrm{a}}\right) \\
& =\left(\frac{1}{2}\right)\left|z_{2 \mathrm{c}} \| z_{2 \mathrm{a}}\right| v_{2} m_{2}
\end{aligned}
$$

Solving for $v_{1} m_{1}$ and $v_{2} m_{2}$ in these equations and inserting the results into the definition of the total ionic strength for the mixture (where $I=I_{1}+I_{2}$ ) yields: 


$$
\begin{aligned}
\left(\frac{\sum_{i=1}^{i=2} v_{i} m_{i}}{I}\right) & =\left(\frac{1}{I}\right)\left(v_{1} m_{1}+v_{2} m_{2}\right) \\
& =\left(\frac{1}{I}\right)\left\{\frac{2 y_{1} I}{\left|z_{1 \mathrm{c}}\right| z_{1 \mathrm{a}} \mid}+\frac{2\left(1-y_{1}\right) I}{\left|z_{2 \mathrm{c}}\right| z_{2 \mathrm{a}} \mid}\right\} \\
& =2\left\{\frac{y_{1}}{\left|z_{\mathrm{lc}}\right| z_{1 \mathrm{a}} \mid}+\frac{\left(1-y_{1}\right)}{\left|z_{2 \mathrm{c}}\right| z_{2 \mathrm{a}} \mid}\right\}
\end{aligned}
$$

and thus

$$
\left(\frac{\sum_{i=1}^{i=2} v_{i} m_{i}}{I}\right)^{2}=4\left\{\frac{y_{1}^{2}}{\left|z_{1 \mathrm{c}}\right|^{2}\left|z_{1 \mathrm{a}}\right|^{2}}+\frac{2\left(y_{1}-y_{1}^{2}\right)}{\left|z_{1 \mathrm{c}}\right|\left|z_{1 \mathrm{a}}\right|\left|z_{2 \mathrm{c}}\right| z_{2 \mathrm{a}} \mid}+\frac{\left(1-2 y_{1}+y_{1}^{2}\right)}{\left|z_{2 \mathrm{c}}\right|^{2}\left|z_{2 \mathrm{a}}\right|^{2}}\right\}
$$

As can be seen, this quantity depends only on the ionic-strength fraction $y_{1}$ of solute 1 (one of the integration variables) and the valences of the ions of both electrolytes, but it is independent of the total ionic strength $I$.

The limits of integration for the integrals of Eqs. $7 \mathrm{a}$ and $7 \mathrm{~b}$ are given as $y_{1}=0$ to $y_{1}=1$ for the ionic strength fraction, and $I=0$ to $I=I_{\max }$ for the total ionic strength. When activity measurements are made with the Emf method, it is common to make them at a series of constant ionic strengths and various values of $y_{1}$ at each $I$. In this case $I_{\max }$ will have a constant value at all $y_{1}$ and the integrals of Eq. $7 \mathrm{~b}$ can easily be evaluated. However, the most commonly used experimental method for measuring thermodynamic activities is the isopiestic method; this method yields the molalities of solutions having identical solvent (water) activities and thus the values of $I_{\max }$ will vary with the ionic-strength fraction of each solute, i.e., $I_{\max }=I_{\max }\left(y_{1}\right)$. Although the integrations of Eq. 7a and $7 \mathrm{~b}$ can still be done once $I_{\max }=I_{\max }\left(y_{1}\right)$ is known, the integrals will be much more complicated to evaluate than if a fixed limit of $I_{\max }=$ constant is imposed. We will thus use the constraint $I_{\max }=$ constant, and then test whether the conversion of mixing parameters for Scatchard's equation is also reliable when the mixing parameters of Eq. 1 are based on isopiestic measurements with a constant water activity cutoff or some other variable upper limit such as when the isopiestic measurements at each value of $y_{1}$ extend to the solubility limit, $I_{\max }=I_{\text {saturation. }}$.

When a constant total ionic strength upper limit of integration $I_{\max }$ is imposed, the two integrals of the denominator of Eq. $7 \mathrm{~b}$ can be separated: 


$$
\begin{aligned}
& \int_{\mathrm{y}_{1}=0}^{\mathrm{y}_{1}=1} \int_{I=0}^{I_{\max }}\left(\frac{\sum_{i=1}^{i=2} v_{i} m_{i}}{I}\right)^{2} \mathrm{~d} I \mathrm{~d} y_{1}=4\left(\int_{I=0}^{I_{\max }} \mathrm{d} I\right) \int_{\mathrm{y}_{1}=0}^{\mathrm{y}_{1}=1}\left\{\frac{y_{1}{ }^{2}}{\left|z_{\mathrm{lc}}\right|^{2}\left|z_{1 \mathrm{a}}\right|^{2}}+\frac{2\left(y_{1}-y_{1}{ }^{2}\right)}{\left|z_{1 \mathrm{c}}\right|\left|z_{1 \mathrm{a}}\right|\left|z_{2 \mathrm{c}}\right|\left|z_{2 \mathrm{a}}\right|}+\frac{\left(1-2 y_{1}+y_{1}{ }^{2}\right)}{\left|z_{2 \mathrm{c}}\right|^{2}\left|z_{2 \mathrm{a}}\right|^{2}}\right\} \mathrm{d} y_{1} \\
& \left.=4 I_{\max }\left\{\frac{y_{1}^{3}}{3\left|z_{1 \mathrm{c}}\right|^{2}\left|z_{1 \mathrm{a}}\right|^{2}}+\frac{\left(y_{1}^{2}-2 y_{1}^{3} / 3\right)}{\left|z_{1 \mathrm{c}}\right|\left|z_{1 \mathrm{a}}\right|\left|z_{2 \mathrm{c}}\right|\left|z_{2 \mathrm{a}}\right|}+\frac{\left(y_{1}-y_{1}^{2}+y_{1}^{3} / 3\right)}{\left|z_{2 \mathrm{c}}\right|^{2}\left|z_{2 \mathrm{a}}\right|^{2}}\right\}\right]_{y_{1}=0}^{y_{1}=1} \\
& =\left(\frac{4}{3}\right) I_{\max }\left\{\frac{1}{\left|z_{1 \mathrm{c}}\right|^{2}\left|z_{1 \mathrm{a}}\right|^{2}}+\frac{1}{\left|z_{1 \mathrm{c}}\right|\left|z_{1 \mathrm{la}}\right|\left|z_{2 \mathrm{c}}\right|\left|z_{2 \mathrm{a}}\right|}+\frac{1}{\left|z_{2 \mathrm{c}}\right|^{2}\left|z_{2 \mathrm{a}}\right|^{2}}\right\} \\
& \equiv D_{\max }
\end{aligned}
$$

For convenience, we define the following two functions:

$$
\begin{aligned}
f\left(\phi^{S}\right) \equiv & \frac{\left(\sum_{i=1}^{2} v_{i} m_{i}\right) \phi^{S}}{I}-\sum_{i=1}^{2}\left(\frac{v_{i} m_{i}}{I}\right) \phi_{i}^{*}=y_{1} y_{2} \sum_{l=0}^{L} \sum_{m=l+1}^{M}\left(y_{1}-y_{2}\right)^{l} I^{m} b_{l m} \\
f\left(\phi^{S, \mathrm{t}}\right) \equiv & \frac{\left(\sum_{i=1}^{2} v_{i} m_{i}\right) \phi^{S, \mathrm{t}}}{I}-\sum_{i=1}^{2}\left(\frac{v_{i} m_{i}}{I}\right) \phi_{i}^{*, \mathrm{t}}=y_{1} y_{2} \sum_{l=0}^{L} \sum_{m=l+1}^{M}\left(y_{1}-y_{2}\right)^{l} I^{m} b_{l m}^{\mathrm{t}}
\end{aligned}
$$

and their difference is given by

$$
\begin{aligned}
\Delta f(\phi) & \equiv f\left(\phi^{S, \mathrm{t}}\right)-f\left(\phi^{S}\right) \\
& =\frac{\left(\sum_{i=1}^{2} v_{i} m_{i}\right)\left(\phi^{S, \mathrm{t}}-\phi^{S}\right)}{I}-\sum_{i=1}^{2}\left(\frac{v_{i} m_{i}}{I}\right)\left(\phi_{i}^{*, \mathrm{t}}-\phi_{i}^{*}\right) \\
& =y_{1}\left(1-y_{1}\right) \sum_{l=0}^{L} \sum_{m=l+1}^{M}\left(2 y_{1}-1\right)^{l} I^{m}\left(b_{l m}^{\mathrm{t}}-b_{l m}\right)
\end{aligned}
$$

where the superscript ${ }^{\mathrm{t}}$ denotes quantities for Scatchard's neutral-electrolyte model [3] where the number of mixing parameters has been truncated. Because the parameters of $\phi_{1}^{*, \mathrm{t}}, \phi_{1}^{*}, \phi_{2}^{*, \mathrm{t}}$, and $\phi_{2}^{*}$ are generally fixed independently using thermodynamic data for the single electrolyte solutions rather than being optimized simultaneously with the mixing parameters, we will let $\phi_{1}^{*, \mathrm{t}}-\phi_{1}^{*}=0$ and $\phi_{2}^{*, \mathrm{t}}-\phi_{2}^{*}=0$. Then, from Eqs. 17 and 5:

$$
\begin{aligned}
\Delta f(\phi) & =\frac{\left(\sum_{i=1}^{2} v_{i} m_{i}\right)\left(\phi^{S, \mathrm{t}}-\phi^{S}\right)}{I} \\
& =y_{1}\left(1-y_{1}\right) \sum_{l=0}^{L} \sum_{m=l+1}^{M}\left(2 y_{1}-1\right)^{l} I^{m}\left(b_{l m}^{\mathrm{t}}-b_{l m}\right)
\end{aligned}
$$


where $b_{l m}^{\mathrm{t}}$ is a mixing parameter of the truncated form of the neutral-electrolyte model (whose value could be zero) corresponding to the known $b_{l m}$ parameter of the source model.

By inserting Eq. 14 and the top line of Eq. 18 into Eq. 7b, we obtain

$$
E_{f, I, y}^{2}=\left(\frac{1}{D_{\max }}\right) \int_{\mathrm{y}_{1}=0}^{\mathrm{y}_{1}=1} \int_{I=0}^{I_{\max }}\{\Delta f(\phi)\}^{2} \mathrm{~d} I \mathrm{~d} y_{1}
$$

The values of the $b_{l m}^{\mathrm{t}}$ parameters that will minimize the value of the mean square error $E_{f, I, y}^{2}$ for the function $\Delta f(\phi)$ (i.e., will thus give the optimum representation of $\phi^{\mathrm{S}}$ with the truncated set of mixing parameters) are obtained by setting equal to zero all of the derivatives $\frac{\partial E_{f, I, y}^{2}}{\partial b_{j k}^{\mathrm{t}}}$ and then simultaneously solving the resulting equations for each $b_{l m}^{\mathrm{t}}$ in terms of the known $b_{l m}$ parameters. Recall that the $\left\{b_{l m}^{\mathrm{t}}\right\}$ set of parameters will have fewer members than the $\left\{b_{l m}\right\}$ set, and may even include the trivial case where all of the $b_{l m}^{\mathrm{t}}=0$. The following derivations will be done for the isothermal case because the parameters of Scatchard's neutral-electrolyte model $[3,4]$ are almost always reported at a single temperature, but these calculations could easily be generalized for temperaturedependent models $[13,14]$ where $b_{l m}=b_{l m}(T)$ and $b_{l m}^{\mathrm{t}}=b_{l m}^{\mathrm{t}}(T)$.

As can be seen from Eq. 18, the factor $\{\Delta f(\phi)\}^{2}$ occurring in Eq. 19 will have many terms but, because they are polynomials in $y_{1}$ and $I$, they can be readily integrated. The complexity of the integrand of Eq. 19 can be simplified by first differentiating under the integral signs rather that doing this after the integrations have been performed. This yields a set of up to six equations of the form:

$$
\begin{aligned}
\frac{\partial E_{f, I, y}^{2}}{\partial b_{j k}^{\mathrm{t}}} & =\left(\frac{1}{D_{\max }}\right) \frac{\partial}{\partial b_{j k}^{\mathrm{t}}}\left[\int_{\mathrm{y}_{1}=0}^{\mathrm{y}_{1}=1 I_{\max }} \int_{I=0}\{\Delta f(\phi)\}^{2} \mathrm{~d} I \mathrm{~d} y_{1}\right] \\
= & \left(\frac{2}{D_{\max }}\right) \int_{\mathrm{y}_{1}=0}^{\mathrm{y}_{1}=1 I_{\max }} \int_{I=0}^{I_{\max }}\{\Delta f(\phi)\}\left\{\frac{\partial \Delta f(\phi)}{\partial b_{j k}^{\mathrm{t}}}\right\} \mathrm{d} I \mathrm{~d} y_{1} \\
= & 0
\end{aligned}
$$

The partial derivatives arising from Eq. 20 can be easily calculated using the general form of $\Delta f(\phi)$ given by Eq. 18: 


$$
\begin{aligned}
& \frac{\partial \Delta f(\phi)}{\partial b_{j k}^{\mathrm{t}}}=y_{1}\left(1-y_{1}\right)\left(2 y_{1}-1\right)^{j} I^{k} \\
& \frac{\partial \Delta f(\phi)}{\partial b_{l m}}=y_{1}\left(1-y_{1}\right)\left(2 y_{1}-1\right)^{l} I^{m}
\end{aligned}
$$

and their values for the six-parameter case are given in Appendix A. Also note that some of the $b_{l m}$ parameters may not be present in the source model and that fewer $b_{l m}^{\mathrm{t}}$ parameters will be used. For those cases the corresponding partial derivatives with respect to the missing parameters will be equal to zero rather than being given by Eqs. $21 \mathrm{a}$ and $21 \mathrm{~b}$.

The function $\Delta f(\phi)$ as given by Eq. 18 is linear in each of the unknown mixing parameters $b_{l m}^{\mathrm{t}}$ and the known mixing parameters $b_{l m}$. Consequently, it can be re-written in the more convenient form

$$
\Delta f(\phi)=\sum_{l=0}^{L} \sum_{m=l+1}^{M}\left\{\left(\frac{\partial \Delta f(\phi)}{\partial b_{l m}^{\mathrm{t}}}\right) b_{l m}^{\mathrm{t}}+\left(\frac{\partial \Delta f(\phi)}{\partial b_{l m}}\right) b_{l m}\right\}
$$

with the additional constraint that the number of mixing parameters of the truncated neutral-electrolyte model $N^{t}<N$, where $N$ is the corresponding number of parameters for the source (non truncated) neutral-electrolyte model. Inserting Eq. 22 into Eq. 20 then yields

$$
\begin{aligned}
\frac{\partial E_{f, I, y}^{2}}{\partial b_{j k}^{\mathrm{t}}} & =\left(\frac{2}{D_{\max }}\right) \int_{\mathrm{y}_{1}=0}^{\mathrm{y}_{1}=1 I_{\max }} \int_{I=0}^{\mathrm{y}_{1}}\{\Delta f(\phi)\}\left\{\frac{\partial \Delta f(\phi)}{\partial b_{j k}^{\mathrm{t}}}\right\} \mathrm{d} I \mathrm{~d} y_{1} \\
& \left.=\left(\frac{2}{D_{\max }}\right) \int_{\mathrm{y}_{1}=0}^{I_{\max }} \int_{I=0}^{L} \sum_{l=0}^{L} \sum_{m=l+1}^{M}\left\{\left(\frac{\partial \Delta f(\phi)}{\partial b_{l m}^{\mathrm{t}}}\right) b_{l m}^{\mathrm{t}}+\left(\frac{\partial \Delta f(\phi)}{\partial b_{l m}}\right) b_{l m}\right\}\left(\frac{\partial \Delta f(\phi)}{\partial b_{j k}^{\mathrm{t}}}\right)\right] \mathrm{d} I \mathrm{~d} y_{1} \\
& =\sum_{l=0}^{L} \sum_{m=l+1}^{M}\left\{\left(\frac{2}{D_{\max }}\right) \int_{\mathrm{y}_{1}=0}^{\mathrm{y}_{1}=1} \int_{I=0}^{I_{\max }}\left(\frac{\partial \Delta f(\phi)}{\partial b_{j k}^{\mathrm{t}}}\right)\left(\frac{\partial \Delta f(\phi)}{\partial b_{l m}^{\mathrm{t}}}\right) \mathrm{d} I \mathrm{~d} y_{1}\right\} b_{l m}^{\mathrm{t}} \\
& +\sum_{l=0}^{L} \sum_{m=l+1}^{M}\left\{\left(\frac{2}{D_{\max }}\right) \int_{\mathrm{y}_{1}=0}^{\mathrm{y}_{1}=1 I_{\max }} \int_{I=0}\left(\frac{\partial \Delta f(\phi)}{\partial b_{j k}^{\mathrm{t}}}\right)\left(\frac{\partial \Delta f(\phi)}{\partial b_{l m}}\right) \mathrm{d} I \mathrm{~d} y_{1}\right\} b_{l m} \\
= & 0
\end{aligned}
$$

where, depending on the number $N$ of $b_{l m}$ parameters in the source model being considered, there may be up to $N$ such equations. Equation 23 can be re-expressed in matrix form as: 
$\sum_{l=0}^{L} \sum_{m=l+1}^{M} A_{j k, l m} b_{l m}^{\mathrm{t}}=\sum_{l=0}^{L} \sum_{m=l+1}^{M} B_{j k, l m} b_{l m}=c_{j k}$

where

$$
\begin{aligned}
& A_{j k, l m} \equiv \int_{\mathrm{y}_{1}=0}^{\mathrm{y}_{1}=1} \int_{I=0}^{I_{\max }}\left(\frac{\partial \Delta f(\phi)}{\partial b_{j k}^{\mathrm{t}}}\right)\left(\frac{\partial \Delta f(\phi)}{\partial b_{l m}^{\mathrm{t}}}\right) \mathrm{d} I \mathrm{~d} y_{1} \\
& B_{j k, l m} \equiv-\int_{\mathrm{y}_{1}=0}^{\mathrm{y}_{1}=1 I_{I=0}} \int_{I=0}^{\max }\left(\frac{\partial \Delta f(\phi)}{\partial b_{j k}^{\mathrm{t}}}\right)\left(\frac{\partial \Delta f(\phi)}{\partial b_{l m}}\right) \mathrm{d} I \mathrm{~d} y_{1}
\end{aligned}
$$

and

$c_{j k} \equiv \sum_{l=0}^{L} \sum_{m=l+1}^{M} B_{j k, l m} b_{l m}$

The integrated forms of $B_{j k, l m}$ are given in Appendix B for the six-parameter case.

Equation 24 is a linear matrix equation for the unknown parameters $b_{l m}^{\mathrm{t}}$ with a constant coefficient matrix $A_{j k, l m}$ and the right-hand side vector $c_{j k}$ that can be evaluated from Eq. 27 using the known source model parameters $b_{l m}$ and the constant coefficient matrix $B_{j k, l m}$. Simultaneous equations of this type can be solved by a standard matrix technique such as Gaussian elimination.

Because we are examining the case where the maximum ionic strength $I_{\max }$ is independent of the ionic-strength fraction $y_{1}$, the integrations over ionic strength and ionic-strength fraction can be performed separately:

$$
\begin{aligned}
B_{j k, l m} & \equiv \int_{y_{1}=0}^{y_{1}=1} \int_{I=0}^{I_{\max }}\left\{y_{1}\left(1-y_{1}\right)\left(2 y_{1}-1\right)^{j} I^{k}\right\}\left\{y_{1}\left(1-y_{1}\right)\left(2 y_{1}-1\right)^{l} I^{m}\right\} \mathrm{d} I \mathrm{~d} y_{1} \\
& =\left(\int_{I=0}^{I_{\max }} I^{k+m} \mathrm{~d} I\right) \int_{y_{1}=0}^{y_{1}=1} y_{1}^{2}\left(1-y_{1}\right)^{2}\left(2 y_{1}-1\right)^{j+l} \mathrm{~d} y_{1} \\
& =\left(\frac{I_{\max }^{k+m+1}}{k+m+1}\right) \int_{z=-1}^{z=+1}\left(\frac{1}{2^{5}}\right)\left(1-z^{2}\right)^{2} z^{j+l} \mathrm{~d} z \\
& =\left(\frac{I_{\max }^{k+m+1}}{k+m+1}\right)\left(\frac{1}{2^{5}}\right) \int_{z=-1}^{z=+1}\left(z^{j+l}-2 z^{j+l+2}+z^{j+l+4}\right) \mathrm{d} z
\end{aligned}
$$

where the third line of Eq. 28 has been obtained by making the substitution of $z=2 y_{1}-$ 1. For a constant value of $I_{\max }$ the last integral can be integrated directly to yield the following closed-form expression for the $B_{j k, l m}$ coefficient matrix elements: 


$$
\begin{aligned}
B_{j k, l m} & =\left\{\frac{I_{\max }^{k+m+1}}{16(k+m+1)}\right\}\left\{\frac{1}{j+l+1}-\frac{2}{j+l+3}+\frac{1}{j+l+5}\right\} \\
& =\left\{\frac{I_{\max }^{k+m+1}}{2(k+m+1)(j+l+1)(j+l+3)(j+l+5)}\right\} \quad \text { when } j+l \text { is even }
\end{aligned}
$$

and

$B_{j k, l m}=0 \quad$ when $j+l$ is odd

Furthermore, the coefficient matrix element $A_{j k, l m}$ can be obtained from the $B_{j k, l m}$ coefficient matrix element by setting

$A_{j k, l m}=B_{j k, l m}$

for all $b_{j k}^{\mathrm{t}} \neq 0$ and $b_{l m}^{\mathrm{t}} \neq 0$. Least-squares minimization treatments of linear functions, such as described above, always produce symmetric coefficient matrices so that both coefficient matrices are symmetrical with respect to their row and column indices. That is,

$$
\begin{aligned}
& A_{j k, l m}=A_{l m, j k} \\
& B_{j k, l m}=B_{l m, j k}
\end{aligned}
$$

As can be seen from Appendix B, 16 of the 36 matrix elements are zero for the six-parameter case when, according to Eq. $29 b, j+l=1$ or 3 (odd number). As an example, the matrices $A_{j k, l m}$ and $B_{j k, l m}$ and the right-hand side vector $c_{j k}$ for the sixparameter source model and four parameter truncated model with non-zero $b_{01}^{\mathrm{t}}, b_{02}^{\mathrm{t}}, b_{12}^{\mathrm{t}}$, and $b_{23}^{\mathrm{t}}$ values are given in Appendix C.

\section{Evaluation of the Parameter Fitting Error}

We have adopted the mean square difference $E_{f, I, y}^{2}$ between the $\Delta f(\phi)$ values calculated using the truncated and full parameter models as the measure of accuracy of fitting of the truncated parameter model to the source model. Therefore, to be able to assess the error, it is necessary to evaluate the value of $E_{f, I, y}^{2}$ after computing the parameters of the truncated model as described in Section 3. There we presented a convenient method of deriving the least-squares minimization equations that avoids direct integration of the 
expression given by Eq. 19 for the mean square error $E_{f, I, y}^{2}$. For complicated higherorder models, these integrals could be evaluated by a numerical quadrature of the function $\{\Delta f(\phi)\}^{2}$, and similarly for the mean square difference in the osmotic coefficient $E_{\phi, I, y}^{2}$ defined by Eq. 7a. However, because of the linearity of the model with respect to the parameters of both the truncated and full parameter models, we are able to compute $E_{f, I, y}^{2}$ analytically. We first define the difference $\Delta b_{l m}$ between the truncated and full parameter model values by

$$
\Delta b_{l m} \equiv b_{l m}^{\mathrm{t}}-b_{l m}
$$

with the understanding that the parameters $b_{l m}^{\mathrm{t}}$ that do not exist in the truncated model are set equal to zero in Eq. 33. Then, noting that

$$
\frac{\partial \Delta f(\phi)}{\partial b_{l m}^{\mathrm{t}}}=-\frac{\partial \Delta f(\phi)}{\partial b_{l m}}=\frac{\partial \Delta f(\phi)}{\partial \Delta b_{l m}}
$$

we are able to recast $\Delta f(\phi)$, given by Eq. 22 , as

$$
\Delta f(\phi)=\sum_{l=0}^{L} \sum_{m=l+1}^{M}\left(\frac{\partial \Delta f(\phi)}{\partial \Delta b_{l m}}\right) \Delta b_{l m}
$$

Substituting this expression into Eq. 19 yields

$$
\begin{aligned}
E_{f, I, y}^{2} & =\left(\frac{1}{D_{\max }}\right) \int_{y_{1}=0}^{y_{1}=1} \int_{I=0}^{I_{\max }}\left[\left\{\sum_{j=0}^{L} \sum_{k=j+1}^{M}\left(\frac{\partial \Delta f(\phi)}{\partial \Delta b_{j k}}\right) \Delta b_{j k}\right\}\left\{\sum_{l=0}^{L} \sum_{m=l+1}^{M}\left(\frac{\partial \Delta f(\phi)}{\partial \Delta b_{l m}}\right) \Delta b_{l m}\right\}\right] \mathrm{d} I \mathrm{~d} y_{1} \\
& =\left(\frac{1}{D_{\max }}\right) \sum_{j=0}^{L} \sum_{k=j+1}^{M} \sum_{l=0}^{L} \sum_{m=l+1}^{M}\left[\int_{y_{1}=0}^{y_{1}=1} \int_{I=0}^{I_{\max }}\left(\frac{\partial \Delta f(\phi)}{\partial \Delta b_{j k}}\right)\left(\frac{\partial \Delta f(\phi)}{\partial \Delta b_{l m}}\right) \mathrm{d} I \mathrm{~d} y_{1}\right] \Delta b_{j k} \Delta b_{l m} \\
& =\left(\frac{1}{D_{\max }}\right) \sum_{j=0}^{L} \sum_{k=j+1}^{M} \sum_{l=0}^{L} \sum_{m=l+1}^{M}\left[B_{j k, l m} \Delta b_{j k} \Delta b_{l m}\right]
\end{aligned}
$$

so that $E_{f, I, y}^{2}$ can be calculated from this equation that is quadratic in $\Delta b_{j k} \Delta b_{l m}$ using the previously calculated values of the coefficient matrix elements $B_{j k, l m}$ and the differences $\Delta b_{l m}$ between the corresponding parameters of the truncated and full parameter models. For the case of $L=2$ and $M=3$, the full expression for $E_{f, I, y}^{2}$ is explicitly given by 


$$
\begin{aligned}
D_{\max } E_{f, I, y}^{2} & =\left(\frac{I_{\max }^{3}}{90}\right) \Delta b_{01} \Delta b_{01}+\left(\frac{I_{\max }^{4}}{120}\right) \Delta b_{01} \Delta b_{02}+\left(\frac{I_{\max }^{5}}{150}\right) \Delta b_{01} \Delta b_{03}+\left(\frac{I_{\max }^{5}}{1050}\right) \Delta b_{01} \Delta b_{23} \\
& +\left(\frac{I_{\max }^{4}}{120}\right) \Delta b_{02} \Delta b_{01}+\left(\frac{I_{\max }^{5}}{150}\right) \Delta b_{02} \Delta b_{02}+\left(\frac{I_{\max }^{6}}{180}\right) \Delta b_{02} \Delta b_{03}+\left(\frac{I_{\max }^{6}}{1260}\right) \Delta b_{02} \Delta b_{23} \\
& +\left(\frac{I_{\max }^{5}}{150}\right) \Delta b_{03} \Delta b_{01}+\left(\frac{I_{\max }^{6}}{180}\right) \Delta b_{03} \Delta b_{02}+\left(\frac{I_{\max }^{7}}{210}\right) \Delta b_{03} \Delta b_{03}+\left(\frac{I_{\max }^{7}}{1470}\right) \Delta b_{03} \Delta b_{23} \\
& +\left(\frac{I_{\max }^{5}}{1050}\right) \Delta b_{12} \Delta b_{12}+\left(\frac{I_{\max }^{6}}{1260}\right) \Delta b_{12} \Delta b_{13} \\
& +\left(\frac{I_{\max }^{6}}{1260}\right) \Delta b_{13} \Delta b_{12}+\left(\frac{I_{\max }^{7}}{1470}\right) \Delta b_{13} \Delta b_{13} \\
& +\left(\frac{I_{\max }^{5}}{1050}\right) \Delta b_{23} \Delta b_{01}+\left(\frac{I_{\max }^{6}}{1260}\right) \Delta b_{23} \Delta b_{02}+\left(\frac{I_{\max }^{7}}{1470}\right) \Delta b_{23} \Delta b_{03}+\left(\frac{I_{\max }^{7}}{4410}\right) \Delta b_{23} \Delta b_{23}
\end{aligned}
$$

This expression for $E_{f, I, y}^{2}$ could also have been obtained by direct analytical integration of Eq. 19, and the minimization equations and coefficient matrix elements $B_{j k, l m}$ given by Eq. 26 can be obtained by differentiating this function with respect to the $\Delta b_{j k}$.

\section{Examples of Parameter Conversions: the $\mathrm{NaCl}+\mathrm{SrCl}_{2}+\mathrm{H}_{2} \mathrm{O}, \mathrm{NaCl}+\mathrm{MgCl}_{2}+$ $\mathrm{H}_{2} \mathrm{O}$, and $\mathrm{MgCl}_{2}+\mathrm{MgSO}_{4}+\mathrm{H}_{2} \mathrm{O}$ Systems}

In this section we give examples of parameter conversions for three systems and compare the results to the corresponding parameter values evaluated directly from the source isopiestic data. Table 1 reports these parameters for the $\mathrm{NaCl}+\mathrm{SrCl}_{2}+\mathrm{H}_{2} \mathrm{O}$ system at $298.15 \mathrm{~K}$ [15] for the ionic-strength range $I_{\max } \leq 6.16 \mathrm{~mol} \cdot \mathrm{kg}^{-1}$ and Table 2 for the full composition range where the upper limits are the crystallization concentrations $I_{\max } \leq 11.2 \mathrm{~mol} \cdot \mathrm{kg}^{-1}$ (very close to saturation for $\mathrm{NaCl}$-rich solutions and probably slightly oversaturated for $\mathrm{SrCl}_{2}$-rich solutions). Similarly, Table 3 lists these parameters

for the $\mathrm{NaCl}+\mathrm{MgCl}_{2}+\mathrm{H}_{2} \mathrm{O}$ system at $298.15 \mathrm{~K}$ [16] for the ionic-strength range $I_{\max } \leq$ $6.2 \mathrm{~mol} \cdot \mathrm{kg}^{-1}$ and Table 4 for the full composition range where the upper limits are the crystallization concentrations $I_{\max } \leq 9.873 \mathrm{~mol} \cdot \mathrm{kg}^{-1}$ (very close to saturation). Table 5 gives the corresponding parameters for the $\mathrm{MgCl}_{2}+\mathrm{MgSO}_{4}+\mathrm{H}_{2} \mathrm{O}$ system at $298.15 \mathrm{~K}$ [12] where the uppermost concentrations are those at isopiestic equilibrium (5.255 $\left.\mathrm{mol} \cdot \mathrm{kg}^{-1} \leq I_{\max } \leq 9.432 \mathrm{~mol} \cdot \mathrm{kg}^{-1}\right)$. We note that for fits to the $\mathrm{NaCl}+\mathrm{SrCl}_{2}+\mathrm{H}_{2} \mathrm{O}$ isopiestic data over the full composition region, only a single set of recommended 
parameters was reported in Ref. [15]. However, the original evaluations were preserved by one of the authors (J.A.R.) and these other parameter sets are also given in Table 2.

The above examples were chosen to compare the reliability of the parameter conversions under three different $I_{\max }$ cutoff conditions. 1) For the $\mathrm{NaCl}+\mathrm{SrCl}_{2}+\mathrm{H}_{2} \mathrm{O}$ and $\mathrm{NaCl}+\mathrm{MgCl}_{2}+\mathrm{H}_{2} \mathrm{O}$ systems the $I_{\max }$ values of the mixtures exceed, on an ionicstrength basis, the range of validity of the equation for the osmotic coefficients of $\mathrm{NaCl}(\mathrm{aq})$. The parameters reported in Tables 1 and 3 correspond to a constant $I_{\max }$ cutoff where the equations used to represent the osmotic coefficients of both limiting binary solutions are valid in this case the cutoff is the ionic strength of saturated $\mathrm{NaCl}(\mathrm{aq})\}$. Because this case corresponds to the $I_{\max }=$ constant cutoff condition used to derive the parameter conversion equations, these parameter conversions should be fairly accurate. 2) For the $\mathrm{NaCl}+\mathrm{SrCl}_{2}+\mathrm{H}_{2} \mathrm{O}$ and $\mathrm{NaCl}+\mathrm{MgCl}_{2}+\mathrm{H}_{2} \mathrm{O}$ systems when the $I_{\max }$ values of the mixtures are constrained by the crystallization limits of the mixtures, Tables 2 and 4 , the equation used to represent the osmotic coefficients of $\mathrm{NaCl}(\mathrm{aq})$ is being employed well above its range of validity. This equation for $\mathrm{NaCl}(\mathrm{aq})$ is of the form of Eq. 2, and equations of this type are not expected to extrapolate reliably much above the highest molality where they are constrained. Thus, the mixing parameters evaluated under this condition not only represent mixing effects but are also compensating to some extent for deficiencies in the extrapolated osmotic coefficients of $\mathrm{NaCl}(\mathrm{aq})$. Both the directly calculated and transformed parameters should be the least accurate under these conditions. 3) For the $\mathrm{MgCl}_{2}+\mathrm{MgSO}_{4}+\mathrm{H}_{2} \mathrm{O}$ system the $I_{\max }$ values of the mixtures are those for isopiestic equilibrium (equal activities of water) and the ionic strengths of all of the mixtures fall within the range of validity of the extended Pitzer equations for the limiting binary solutions. The parameter conversions in this case should not be as accurate as for case 1, but are expected be more accurate than for case 2 .

The converted parameters obtained with the constant constraint $I_{\max }=6.16$ $\mathrm{mol} \cdot \mathrm{kg}^{-1}$ or $I_{\max }=6.2 \mathrm{~mol} \cdot \mathrm{kg}^{-1}$, reported in Tables 1 and 3 for the $\mathrm{NaCl}+\mathrm{SrCl}_{2}+\mathrm{H}_{2} \mathrm{O}$ and $\mathrm{NaCl}+\mathrm{MgCl}_{2}+\mathrm{H}_{2} \mathrm{O}$ systems, respectively, are generally close to those obtained by direct fitting, especially for the $b_{01}, b_{02}$ and $b_{03}$ mixing parameters that represent the (dominant) symmetrical mixing effects. Not surprisingly, for the $b_{12}$ and $b_{13}$ mixing parameters that represent the much smaller asymmetric mixing effects, the agreement is 
not as good. It is also probable that the converted parameters for the truncated models, calculated as described above, are generally more accurate than those obtained by direct fitting especially when the model contains too few model parameters to represent the source data to near experimental accuracy. This is because when certain mixing terms that are needed to represent the experimental osmotic coefficients are missing, the parameters of other terms obtained by least squares will change in an attempt to compensate for the missing terms.

As anticipated, the agreement between the converted and directly evaluated mixing parameters reported in Tables 2, 4, and 5 is not as good as those of Tables 1 and 3 because the value of $I_{\max }$ were not constant in the direct (least-squares) evaluations, whereas $I_{\max }$ was assumed to be constant for the parameter conversions.

For the converted parameters, when a particular combination of mixing parameters for symmetrical mixing $\left(b_{01}\right.$ and/or $b_{02}$ and/or $\left.b_{03}\right)$ is used, their values are unaffected by the presence or absence of parameters for the first asymmetrical-mixing term $\left(b_{12}\right.$ and/or $\left.b_{13}\right)$. Similarly, when a particular combination of parameters for asymmetrical mixing $\left(b_{12}\right.$ and/or $\left.b_{13}\right)$ is used, their values are unaffected by the presence or absence of parameters for symmetrical mixing $\left(b_{01}\right.$ and/or $b_{02}$ and/or $\left.b_{03}\right)$. This is because the corresponding partial derivatives that occur in the integrals for $A_{j k, l m}$ and $B_{j k, l m}$, Eqs. 25 and 26, are orthogonal and their corresponding integrals are zero as shown in Appendix $\mathrm{B}$, as a consequence of the mixing terms with $b_{0 i}$ coefficients being even functions of $y_{1}$ whereas the mixing terms with $b_{1 i}$ coefficients are odd functions of $y_{1}$. However, the mixing term with $b_{23}$ is an even function of $y_{1}$, so its presence affects the transformed values of $b_{01}, b_{02}$ and $b_{03}$, but not those of $b_{12}$ and $b_{13}$.

The above direct comparison of parameters gives an incomplete picture of the reliability of the converted parameters. A direct comparison between values of the osmotic coefficients calculated with a particular converted parameter set, and the corresponding set obtained directly by least-squares analysis of the experimental source data, should be a better test for the accuracy of our parameter conversion method. This comparison was done and plots were made of the calculated differences in osmotic coefficients as a function of the total ionic strength at fixed values of $y_{1}=(0.1$. 0.2, 0.3 , $0.4,0.5,0.6,0.7,0.8$, and 0.9 ) for several parameter sets for each of the five test 
systems. For calculations representing models that apply to the highest experimental ionic strengths (i.e., for the mixing coefficients given in Tables 2, 4, and 5), the plots extend only to the values of $I_{\max }$ at each value of $y_{1}$ (which were estimated graphically and are summarized in Table 6) rather than to the highest (constant) value of $I_{\max }$ that was assumed when making the parameter transformation. That is, the plots only extend to the highest ionic strengths where isopiestic data was available to constrain the source model.

Figures 1 to 6 show these osmotic coefficient differences for the two cases where our parameter conversion method is expected to be most accurate: the $\mathrm{NaCl}+\mathrm{SrCl}_{2}+$ $\mathrm{H}_{2} \mathrm{O}$ system with $I_{\max } \leq 6.16 \mathrm{~mol} \cdot \mathrm{kg}^{-1}$ (Table 1 coefficients) and the $\mathrm{NaCl}+\mathrm{MgCl}_{2}+$ $\mathrm{H}_{2} \mathrm{O}$ system with $I_{\max } \leq 6.2 \mathrm{~mol} \cdot \mathrm{kg}^{-1}$ (Table 3 coefficients). For both of these systems the illustrated cases are for the parameter sets $\left\{b_{01}\right\},\left\{b_{01}, b_{02}, b_{03}\right\}$, and the set with one fewer parameter than the source model: $\left\{b_{01}, b_{02}, b_{03}, b_{12}\right\}$ for $\mathrm{NaCl}+\mathrm{SrCl}_{2}+\mathrm{H}_{2} \mathrm{O}$ and $\left\{b_{01}, b_{02}, b_{03}, b_{12}, b_{13}\right\}$ for $\mathrm{NaCl}+\mathrm{MgCl}_{2}+\mathrm{H}_{2} \mathrm{O}$. In these plots the largest differences are seen to be $\Delta \phi<0.0008$, which is less than the typical 0.1 to $0.2 \%$ uncertainty of the isopiestic data used to evaluate the parameters of the source models. We also note that the $\Delta \phi$ deviations are linear and all of one sign, as expected, when only the single $b_{01}$ parameter is used, see Figs. 1 and 4. For a very few of the parameter combinations given in Tables 1 and 3, not illustrated, there are maximum differences $\Delta \phi$ of about twice as large as the illustrated cases but only at high ionic strengths and with certain values of $y_{1}$. For the majority of the parameter combinations $\Delta \phi<0.0008$ and consequently the converted parameters yield representations of the source data as accurate as those obtained directly by direct least-squares fits to the source data.

When the directly evaluated source model parameters are based on experimental data where the ionic strength cutoff varied with the ionic-strength fraction, such as when they are constrained by isopiestic ionic strengths $\left(\mathrm{MgCl}_{2}+\mathrm{MgSO}_{4}+\mathrm{H}_{2} \mathrm{O}\right.$, Table 5 coefficients) or solubility / oversaturation ionic strengths $\left(\mathrm{NaCl}+\mathrm{SrCl}_{2}+\mathrm{H}_{2} \mathrm{O}\right.$, Table 2 coefficients; $\mathrm{NaCl}+\mathrm{MgCl}_{2}+\mathrm{H}_{2} \mathrm{O}$; Table 4 coefficients), then parameters converted by this approach assuming a constant ionic-strength cutoff yield $\operatorname{RMSE}(\phi)$ differences about an order of magnitude larger than for the cases described in the previous paragraph. We restrict the plots for these cases, Figs. 7 to 9 , to the parameter set $\left\{b_{01}\right.$, 
$\left.b_{02}, b_{03}\right\}$. It is evident from these figures that the values of $\Delta \phi$ for this parameter set are one to two orders of magnitude larger than those for the $I_{\max }=$ constant case, and thus this assumption does not yield accurate parameter transformations when the source model was based on ionic strength cutoffs that vary with the value of $y_{1}$. We note, however, that the representations for $\mathrm{NaCl}+\mathrm{SrCl}_{2}+\mathrm{H}_{2} \mathrm{O}$ (Fig. 7) and $\mathrm{NaCl}+\mathrm{MgCl}_{2}+$ $\mathrm{H}_{2} \mathrm{O}$ (Fig. 8) are much better up to $I \cong 6 \mathrm{~mol} \cdot \mathrm{kg}^{-1}$, where the $\mathrm{NaCl}$ (aq) binary solution model parameters are constrained, than at higher concentrations where the $\mathrm{NaCl}(\mathrm{aq})$ is being extrapolated. However, for some other parameter sets these larger deviations begin to occur at lower ionic strengths. For the condition where the $I_{\max }$ cutoffs vary with $y_{1}$, an extension of our approach will be required to yield accurate parameter conversions.

In deciding whether a particular truncated model with fewer parameters obtained by our parameter conversion method gives an adequate representation of the source data, the errors from converting the parameters from the source fits with a larger number of parameters to those of a truncated model with fewer parameters, $\operatorname{RMSE}(\Delta \phi)$, also need to be considered. Table 7 reports these $\operatorname{RMSE}(\Delta \phi)$ values for all of the model parameter sets reported in Tables 1 to 5. The order of these $\operatorname{RMSE}(\Delta \phi)$ values approximately follows those of the standard deviations $\sigma(\phi)$ obtained by direct fitting $[12,15,16]$, with those truncated models with the smallest values of $\operatorname{RMSE}(\Delta \phi)$ generally having the smallest values of $\sigma(\phi)$, and those with the largest values of $\operatorname{RMSE}(\Delta \phi)$ generally having the largest values of $\sigma(\phi)$. In addition, for all of the parameter combinations for $\mathrm{NaCl}+$ $\mathrm{SrCl}_{2}+\mathrm{H}_{2} \mathrm{O}$ with $I \leq 6.16 \mathrm{~mol} \cdot \mathrm{kg}^{-1}$ (Table 1) and $\mathrm{NaCl}+\mathrm{MgCl}_{2}+\mathrm{H}_{2} \mathrm{O}$ with $I \leq 6.2$ $\mathrm{mol} \cdot \mathrm{kg}^{-1}$ (Table 3 ), the values of $\sigma(\phi)$ obtained by direct fitting are slightly larger than the corresponding $\operatorname{RMSE}(\Delta \phi)$ values with the difference generally being less than 0.001 . This is also the case for the $\mathrm{NaCl}+\mathrm{MgCl}_{2}+\mathrm{H}_{2} \mathrm{O}$ system with $I \leq 9.873 \mathrm{~mol} \cdot \mathrm{kg}^{-1}$ (Table 4). In contrast, for $\mathrm{MgCl}_{2}+\mathrm{MgSO}_{4}+\mathrm{H}_{2} \mathrm{O}$ with $I \leq 9.432 \mathrm{~mol} \cdot \mathrm{kg}^{-1}$ (Table 5) the values of $\sigma(\phi)$ obtained by direct fitting are slightly smaller than the corresponding $\operatorname{RMSE}(\Delta \phi)$ values, whereas for $\mathrm{NaCl}+\mathrm{SrCl}_{2}+\mathrm{H}_{2} \mathrm{O}$ with $I \leq 9.873 \mathrm{~mol} \cdot \mathrm{kg}^{-1}$ (Table 2) the values of $\operatorname{RMSE}(\Delta \phi)$ are sometimes larger and sometimes smaller than $\sigma(\phi)$. Thus, although $\operatorname{RMSE}(\Delta \phi)$ appears to be a good predictor of the reliability of converted truncated 
models when the source model is based on an $I_{\max }=$ constant cutoff, it is not a reliable measure of accuracy in representing the source data when $I_{\max }$ is a function of the ionic strength fraction $y_{1}$.

\section{Conclusions}

This paper describes an analytical method for transforming the mixing parameters of Scatchard's neutral-electrolyte-type models with larger numbers of mixing parameters directly to those of models with fewer mixing parameters, without recourse to the source data used for evaluation of the original model parameters. The resulting analytical transformation equations are evaluated explicitly for the case where the original source model parameters (ternary system) were evaluated with a maximum ionic strength cutoff that is independent of the ionic strength fraction of the electrolytes. A comparison for two test systems, $\mathrm{NaCl}+\mathrm{SrCl}_{2}+\mathrm{H}_{2} \mathrm{O}$ and $\mathrm{NaCl}+\mathrm{MgCl}_{2}+\mathrm{H}_{2} \mathrm{O}$ with a constant ionic strength cutoff corresponding to the saturated $\mathrm{NaCl}(\mathrm{aq})$ solution ionic strength, indicated that 1) osmotic coefficients calculated from the transformed parameter sets are in excellent agreement with those calculated with the corresponding parameters evaluated directly from isopiestic data, and 2) the calculated errors for the osmotic coefficient from reducing the number of model parameters corresponds well with the standard deviation for the corresponding parameter sets obtained by direct fitting. Thus, our parameter transformation method yields excellent results under these conditions.

When the source model parameters were evaluated at maximum ionic strengths that vary with the ionic strength fractions of the solute, osmotic coefficients calculated from the parameters transformed under the assumption of a constant ionic strength are significantly less reliable, but the uncertainty varies on a case-by-case basis. Because of this, we cannot recommend our method under these conditions. However, if $I_{\max }$ is a smooth function of $y_{1}$, as occurs for example when the values of $I_{\max }$ correspond to isopiestic equilibrium conditions, it should be possible to represent $I_{\max }$ as a simple polynomial of $y_{1}$. Although the resulting transformation equations should still have analytical solutions, they will be much more complicated than those reported here for the $I_{\max }=$ constant case. Furthermore, if the values of $I_{\max }$ are not a smooth function of 
$y_{1}$, such as when they as based on saturated solution molalities with more than one precipitating phase, then it may be necessary to switch from analytical integration to numerical quadruture of the transformation integrals. These refinements are beyond the scope of the present paper.

\section{Acknowledgment}

This work was performed under the auspices of the U.S. Department of Energy by Lawrence Livermore National Laboratory under Contract DE-AC52-07NA27344.

\section{References}

1. Harned, H.S., Owen, B.B.: The Physical Chemistry of Electrolyte Solutions. Reinhold Publishing Corp., New York (1958)

2. Robinson, R.A., Stokes, R.H.: Electrolyte Solutions, $2^{\text {nd }}$ ed. (revised). Butterworths, London (1965), pp. 432-455

3. Scatchard, G.: Osmotic coefficients and activity coefficients in mixed electrolyte solutions. J. Am. Chem. Soc. 83, 2636-2642 (1961)

4. Rush, R.M.: Parameters for the Calculation of Osmotic and Activity Coefficients and Tables of these Coefficients for Twenty-two Aqueous Mixtures of Two Electrolytes at $25^{\circ} \mathrm{C}$. Oak Ridge National Laboratory report ORNL-4402, Oak Ridge (1969)

5. Friedman, H.L.: Ionic strength dependence in dilute common-ion mixtures. J. Solution Chem. 9, 525-533 (1980)

6. Wigent, R.J., Leifer, L.: Determination of osmotic and activity coefficients in mixed electrolyte systems. Systems containing clathrate-forming salts. J. Phys. Chem. 88, 4420-4426 (1984)

7. Leifer, L., Wigent, R.J.: Determination of the contribution of pair, triplet, and higherorder mutliplet interactions to the excess free energy of mixing in mixed electrolyte solutions. J. Phys. Chem. 89, 244-245 (1985)

8. Blandamer, M.J., Engberts, J.B.F.N., Gleeson, P.T., Reis, J.C.R.: Activity of water in aqueous systems; a frequently neglected property. Chem. Soc. Rev. 34, 440-458 (2005) 
9. Pitzer, K.S.: Ion Interaction Approach: Theory and Data Correlation. In: Pitzer, K.S. (ed.) Activity Coefficients in Electrolyte Solutions, 2nd edn., CRC Press, Boca Raton (1991), Chap. 3

10. Clegg, S.L., Whitfield, M.: Activity Coefficients in Natural Waters. In: Pitzer, K.S. (ed.) Activity Coefficients in Electrolyte Solutions, 2nd edn., CRC Press, Boca Raton (1991), Chap. 6

11. Pavićević, V., Ninković, R., Todorović, M., Miladinović, J.: Osmotic and activity coefficients of $\left\{y \mathrm{NaH}_{2} \mathrm{PO}_{4}+(1-y) \mathrm{Na}_{2} \mathrm{SO}_{4}\right\}$ (aq) at the temperature $298.15 \mathrm{~K}$. Fluid Phase Equil. 164, 275-284 (1999)

12. Miladinović, J., Ninković, R., Todorović, M., Rard, J.A.: Isopiestic investigation of the osmotic and activity coefficients of $\left\{y \mathrm{MgCl}_{2}+(1-y) \mathrm{MgSO}_{4}\right\}$ (aq) and the osmotic coefficients of $\mathrm{Na}_{2} \mathrm{SO}_{4} \cdot \mathrm{MgSO}_{4}$ (aq) $298.15 \mathrm{~K}$. J. Solution Chem. 37, 307-329 (2008)

13. Rard, J.A., Wijesinghe, A.M.: Conversion of parameters between different variants of Pitzer's ion-interaction model, both with and without ionic strength dependent higherorder terms. J. Chem. Thermodyn. 35, 439-473 (2003)

14. Wijesinghe, A.M., Rard, J.A.: Conversion and optimization of the parameters from an extended form of the ion-interaction model for $\mathrm{Ca}\left(\mathrm{NO}_{3}\right)_{2}(\mathrm{aq})$ and $\mathrm{NaNO}_{3}(\mathrm{aq})$ to those of the standard Pitzer model, and an assessment of the accuracy of the parameter temperature representations. J. Chem. Thermodyn. 37, 1196-1218 (2005)

15. Rard, J.A., Miller, D.G.: Isopiestic determination of the osmotic and activity coefficients of aqueous mixtures of $\mathrm{NaCl}$ and $\mathrm{SrCl}_{2}$ at $25{ }^{\circ} \mathrm{C}$. J. Chem. Eng. Data 27, 342-346 (1982)

16. Rard, J.A., Miller, D.G.: Isopiestic determination of the osmotic and activity coefficients of aqueous mixtures of $\mathrm{NaCl}$ and $\mathrm{MgCl}_{2}$ at $25^{\circ} \mathrm{C}$. J. Chem. Eng. Data 32 , 85-92 (1987)

17. Archer, D.G., Rard, J.A.: Isopiestic investigation of the osmotic and activity coefficients of aqueous $\mathrm{MgSO}_{4}$ and the solubility of $\mathrm{MgSO}_{4} \cdot 7 \mathrm{H}_{2} \mathrm{O}$ (cr) at $298.15 \mathrm{~K}$ : thermodynamic properties of the $\mathrm{MgSO}_{4}+\mathrm{H}_{2} \mathrm{O}$ system to $440 \mathrm{~K}$. J. Chem. Eng. Data 43, 791-806 (1998); correction. J. Chem. Eng. Data 45, 716 (2000) 
18. Pitzer, K.S. Wang, P., Rard, J.A., Clegg, S.L.: Thermodynamics of electrolytes. 13. Ionic-strength dependence of higher-order terms; equations for $\mathrm{CaCl}_{2}$ and $\mathrm{MgCl}_{2} . \mathrm{J}$. Solution Chem. 28, 265-282 (1999)

19. Wang, Z.-C., He, M., Wang, J., Li, J.-L.: Modeling of aqueous 3-1 rare earth electrolytes and their mixtures to very high concentrations. J. Solution Chem. 35, 1137-1156 (2006)

20. Pitzer, K.S., Simonson, J.M.: Thermodynamics of multicomponent, miscible, ionic systems: theory and equations. J. Phys. Chem. 90, 3005-3009 (1986)

21. Clegg, S.L., Pitzer, K.S.: Thermodynamics of multicomponent, miscible, ionic solutions: Generalized equations for symmetrical electrolytes. J. Phys. Chem. 96, 3513-3520 (1992); additions and corrections. J. Phys. Chem. 98, 1368 (1994)

22. Clegg, S.L., Pitzer, K.S., Brimblecombe, P.: Thermodynamics of multicomponent, miscible, ionic solutions. 2. Mixtures including unsymmetrical electrolytes. J. Phys. Chem. 96, 9470-9479 (1992); additions and corrections. J. Phys. Chem. 98, 1368 (1994) 
Table 1 Parameters for Scatchard's neutral-electrolyte model for $\mathrm{NaCl}+\mathrm{SrCl}_{2}+\mathrm{H}_{2} \mathrm{O}$ at $298.15 \mathrm{~K}$ based on the five-parameter source model with $I \leq 6.16 \mathrm{~mol} \cdot \mathrm{kg}^{-1}[15]$ and various models with a reduced number of model parameters ${ }^{\text {a }}$

\begin{tabular}{|c|c|c|c|c|c|}
\hline$b_{01}$ & $b_{02}$ & $b_{03}$ & $b_{12}$ & $b_{13}$ & $\begin{array}{l}\operatorname{RMSE}(\phi) \text { and } \\
\operatorname{RMSE}(f)\end{array}$ \\
\hline$+6.239 \times 10^{-3}$ & & & & & $0.00010(0.00009)$ \\
\hline \multicolumn{6}{|l|}{$\left(+6.02 \times 10^{-3}\right)$} \\
\hline$+1.920 \times 10^{-2}$ & $-2.806 \times 10^{-3}$ & & & & $0.00062(0.00059)$ \\
\hline$\left(+1.458 \times 10^{-2}\right)$ & $\left(-2.03 \times 10^{-3}\right)$ & & & & \\
\hline$+5.240 \times 10^{-3}$ & $+4.750 \times 10^{-3}$ & $-9.200 \times 10^{-4}$ & & & $0.00029(0.00028)$ \\
\hline$\left(+5.53 \times 10^{-3}\right)$ & $\left(+4.30 \times 10^{-3}\right)$ & $\left(-8.7 \times 10^{-4}\right)$ & & & \\
\hline$+5.240 \times 10^{-3}$ & $+4.750 \times 10^{-3}$ & $-9.200 \times 10^{-4}$ & $-1.473 \times 10^{-3}$ & & $0.00006(0.00006)$ \\
\hline$\left(+5.44 \times 10^{-3}\right)$ & $\left(+4.49 \times 10^{-3}\right)$ & $\left(-8.8 \times 10^{-4}\right)$ & $\left(-1.47 \times 10^{-3}\right)$ & & \\
\hline$\left(+5.24 \times 10^{-3}\right)^{b}$ & $\left(+4.75 \times 10^{-3}\right)^{b}$ & $\left(-9.2 \times 10^{-4}\right)^{b}$ & $\left(-2.91 \times 10^{-3}\right)^{b}$ & $\left(+2.8 \times 10^{-4}\right)^{b}$ & $0.00098^{b}$ \\
\hline$+1.920 \times 10^{-2}$ & $-2.806 \times 10^{-3}$ & & $-1.473 \times 10^{-3}$ & & $0.00052(0.00050)$ \\
\hline$\left(+1.455 \times 10^{-2}\right)$ & $\left(-1.88 \times 10^{-3}\right)$ & & $\left(-1.46 \times 10^{-3}\right)$ & & \\
\hline$+1.920 \times 10^{-2}$ & $-2.806 \times 10^{-3}$ & & $-2.910 \times 10^{-3}$ & $+2.800 \times 10^{-4}$ & $0.00056(0.00050)$ \\
\hline$\left(+1.464 \times 10^{-2}\right)$ & $\left(-1.90 \times 10^{-3}\right)$ & & $\left(-1.92 \times 10^{-3}\right)$ & $\left(+0.9 \times 10^{-4}\right)$ & \\
\hline$+6.239 \times 10^{-3}$ & & & $-1.473 \times 10^{-3}$ & & $0.00022(0.00019)$ \\
\hline$\left(+6.65 \times 10^{-3}\right)$ & & & $\left(-1.57 \times 10^{-3}\right)$ & & \\
\hline$+6.239 \times 10^{-3}$ & & & $-2.910 \times 10^{-3}$ & $+2.800 \times 10^{-4}$ & $0.00035(0.00032)$ \\
\hline \multirow[t]{9}{*}{$\left(+6.64 \times 10^{-3}\right)$} & & & $\left(-0.95 \times 10^{-3}\right)$ & $\left(-1.2 \times 10^{-4}\right)$ & \\
\hline & $+7.302 \times 10^{-3}$ & $-1.210 \times 10^{-3}$ & & & $0.00030(0.00029)$ \\
\hline & $\left(+7.37 \times 10^{-3}\right)$ & $\left(-1.25 \times 10^{-3}\right)$ & & & \\
\hline & $+7.302 \times 10^{-3}$ & $-1.210 \times 10^{-3}$ & $-1.473 \times 10^{-3}$ & & $0.00007(0.00007)$ \\
\hline & $\left(+7.51 \times 10^{-3}\right)$ & $\left(-1.25 \times 10^{-3}\right)$ & $\left(-1.47 \times 10^{-3}\right)$ & & \\
\hline & $+7.302 \times 10^{-3}$ & $-1.210 \times 10^{-3}$ & $-2.910 \times 10^{-3}$ & $+2.800 \times 10^{-4}$ & $0.00015(0.00013)$ \\
\hline & $\left(+7.68 \times 10^{-3}\right)$ & $\left(-1.28 \times 10^{-3}\right)$ & $\left(-3.08 \times 10^{-3}\right)$ & $\left(+3.2 \times 10^{-4}\right)$ & \\
\hline & $+1.091 \times 10^{-3}$ & & $-2.910 \times 10^{-3}$ & $+2.800 \times 10^{-4}$ & $0.00044(0.00040)$ \\
\hline & $\left(+1.15 \times 10^{-3}\right)$ & & $\left(-6 \times 10^{-5}\right)$ & $\left(-3.0 \times 10^{-4}\right)$ & \\
\hline
\end{tabular}

${ }^{a}$ Units: $b_{01}, \mathrm{~kg} \cdot \mathrm{mol}^{-1} ; b_{02}$ and $b_{12}, \mathrm{~kg}^{2} \cdot \mathrm{mol}^{-2} ; b_{03}$ and $b_{13}, \mathrm{~kg}^{3} \cdot \mathrm{mol}^{-3} \cdot \operatorname{RMSE}(\phi)$ and $\operatorname{RMSE}(f)$ (given in parentheses) denote the root-mean-square error in the osmotic coefficient and in $\Delta f$, respectively, resulting from the parameter conversion step only; their values do not include errors from the five-parameter source model. Each set of derived parameters is followed by the reported set [15] (given in parentheses) that was obtained by direct least-squares analysis of the experimental osmotic coefficients 
${ }^{\mathrm{b}}$ Source model parameters and $\operatorname{RMSE}(\phi)$ from direct fit to experimental osmotic coefficients 
Table 2 Parameters for Scatchard's neutral-electrolyte model for $\mathrm{NaCl}+\mathrm{SrCl}_{2}+\mathrm{H}_{2} \mathrm{O}$ at $298.15 \mathrm{~K}$ based on the five-parameter source model with $I \leq 11.2 \mathrm{~mol} \cdot \mathrm{kg}^{-1}[15]$ and various models with a reduced number of model parameters ${ }^{\text {a }}$

\begin{tabular}{|c|c|c|c|c|c|}
\hline$b_{01}$ & $b_{02}$ & $b_{03}$ & $b_{12}$ & $b_{13}$ & $\begin{array}{l}\operatorname{RMSE}(\phi) \text { and } \\
\operatorname{RMSE}(f)\end{array}$ \\
\hline$-1.458 \times 10^{-2}$ & & & & & $0.01210(0.01158)$ \\
\hline \multicolumn{6}{|l|}{$\left(+4.06 \times 10^{-4}\right)$} \\
\hline$+3.536 \times 10^{-2}$ & $-5.945 \times 10^{-3}$ & & & & $0.00814(0.00779)$ \\
\hline$\left(+1.780 \times 10^{-2}\right)$ & $\left(-2.938 \times 10^{-3}\right)$ & & & & \\
\hline$+0.927 \times 10^{-2}$ & $+1.82 \times 10^{-3}$ & $-5.20 \times 10^{-4}$ & & & $0.00723(0.00692)$ \\
\hline$\left(+1.331 \times 10^{-2}\right)$ & $\left(-1.074 \times 10^{-3}\right)$ & $\left(-1.62 \times 10^{-4}\right)$ & & & \\
\hline$+0.927 \times 10^{-2}$ & $+1.82 \times 10^{-3}$ & $-5.20 \times 10^{-4}$ & $-1.830 \times 10^{-3}$ & & $0.00109(0.00116)$ \\
\hline$\left(+1.022 \times 10^{-2}\right)$ & $\left(+1.280 \times 10^{-3}\right)$ & $\left(-4.59 \times 10^{-4}\right)$ & $\left(-1.583 \times 10^{-3}\right)$ & & \\
\hline$\left(+0.927 \times 10^{-2}\right)^{b}$ & $\left(+1.82 \times 10^{-3}\right)^{b}$ & $\left(-5.2 \times 10^{-4}\right)^{\mathrm{b}}$ & $\left(-9.9 \times 10^{-4}\right)^{b}$ & $\left(-9.0 \times 10^{-5}\right)^{b}$ & $0.00147^{b}$ \\
\hline$+3.536 \times 10^{-2}$ & $-5.945 \times 10^{-3}$ & & $-1.830 \times 10^{-3}$ & & $0.00608(0.00630)$ \\
\hline$\left(+2.074 \times 10^{-2}\right)$ & $\left(-3.550 \times 10^{-3}\right)$ & & $\left(-9.12 \times 10^{-4}\right)$ & & \\
\hline$-1.458 \times 10^{-2}$ & & & $-1.830 \times 10^{-3}$ & & $0.01253(0.01332)$ \\
\hline \multirow[t]{5}{*}{$\left(+8.03 \times 10^{-4}\right)$} & & & $\left(+5.38 \times 10^{-4}\right)$ & & \\
\hline & $+4.303 \times 10^{-3}$ & $-6.752 \times 10^{-4}$ & & & $0.00600(0.00575)$ \\
\hline & $\left(+3.282 \times 10^{-3}\right)$ & $\left(-4.85 \times 10^{-4}\right)$ & & & \\
\hline & $+4.303 \times 10^{-3}$ & $-6.752 \times 10^{-4}$ & $-1.830 \times 10^{-3}$ & & $0.00070(0.00065)$ \\
\hline & $\left(+4.777 \times 10^{-3}\right)$ & $\left(-7.32 \times 10^{-4}\right)$ & $\left(-1.764 \times 10^{-3}\right)$ & & \\
\hline
\end{tabular}

${ }^{\mathrm{a}}$ Units: $b_{01}, \mathrm{~kg} \cdot \mathrm{mol}^{-1} ; b_{02}$ and $b_{12}, \mathrm{~kg}^{2} \cdot \mathrm{mol}^{-2} ; b_{03}$ and $b_{13}, \mathrm{~kg}^{3} \cdot \mathrm{mol}^{-3}$. RMSE $(\phi)$ and $\operatorname{RMSE}(f)$ (given in parentheses) denote the root-mean-square error in the osmotic coefficient and in $\Delta f$, respectively, resulting from the parameter conversion step only; their values do not include errors from the five-parameter source model. Each set of derived parameters is followed by the set (given in parentheses) that was obtained by direct least-squares analysis of the experimental osmotic coefficients. Most of these values were not given in the source paper and are taken from the original computer printout

${ }^{\mathrm{b}}$ Source model parameters and $\operatorname{RMSE}(\phi)$ from direct fit to experimental osmotic coefficients 
Table 3 Parameters for Scatchard's neutral-electrolyte model for $\mathrm{NaCl}+\mathrm{MgCl}_{2}+\mathrm{H}_{2} \mathrm{O}$ at $298.15 \mathrm{~K}$ based on the six-parameter source model with $I \leq 6.2 \mathrm{~mol} \cdot \mathrm{kg}^{-1}$ [16] and various models with a reduced number of model parameters ${ }^{\mathrm{a}}$

\begin{tabular}{|c|c|c|c|c|c|c|}
\hline$b_{01}$ & $b_{02}$ & $b_{03}$ & $b_{12}$ & $b_{13}$ & $b_{23}$ & $\begin{array}{l}\operatorname{RMSE}(\phi) \\
\text { and } \\
\operatorname{RMSE}(f)\end{array}$ \\
\hline$+2.960 \times 10^{-2}$ & & & & & & $0.00033(0.00032)$ \\
\hline \multicolumn{7}{|l|}{$\left(+3.034 \times 10^{-2}\right)$} \\
\hline$+3.971 \times 10^{-2}$ & $-2.173 \times 10^{-3}$ & & & & & $0.00041(0.00040)$ \\
\hline$\left(+4.292 \times 10^{-2}\right)$ & $\left(-2.724 \times 10^{-3}\right)$ & & & & & \\
\hline$+4.695 \times 10^{-2}$ & $-6.067 \times 10^{-3}$ & $+4.710 \times 10^{-4}$ & & & & $0.00038(0.00037)$ \\
\hline$\left(+4.844 \times 10^{-2}\right)$ & $\left(-5.807 \times 10^{-3}\right)$ & $\left(+3.80 \times 10^{-4}\right)$ & & & & \\
\hline$+4.695 \times 10^{-2}$ & $-6.067 \times 10^{-3}$ & $+4.710 \times 10^{-4}$ & $-1.407 \times 10^{-3}$ & & & $0.00042(0.00041)$ \\
\hline$\left(+4.679 \times 10^{-2}\right)$ & $\left(-4.960 \times 10^{-3}\right)$ & $\left(+2.58 \times 10^{-4}\right)$ & $\left(-1.622 \times 10^{-3}\right)$ & & & \\
\hline$+4.695 \times 10^{-2}$ & $-6.067 \times 10^{-3}$ & $+4.710 \times 10^{-4}$ & $-1.073 \times 10^{-2}$ & $+1.804 \times 10^{-3}$ & & $0.00014(0.00013)$ \\
\hline$\left(+4.665 \times 10^{-2}\right)$ & $\left(-5.852 \times 10^{-3}\right)$ & $\left(+4.41 \times 10^{-4}\right)$ & $\left(-1.055 \times 10^{-2}\right)$ & $\left(+1.740 \times 10^{-3}\right)$ & & \\
\hline \multirow[t]{3}{*}{$\left(+4.695 \times 10^{-2}\right)^{\mathrm{b}}$} & $\left(-6.067 \times 10^{-3}\right)^{b}$ & $\left(+4.39 \times 10^{-4}\right)^{b}$ & $\left(-1.073 \times 10^{-2}\right)^{b}$ & $\left(+1.804 \times 10^{-3}\right)^{b}$ & $\left(+2.24 \times 10^{-4}\right)^{\mathrm{b}}$ & $0.00208^{\mathrm{b}}$ \\
\hline & $+5.832 \times 10^{-3}$ & & & & & $0.00022(0.00021)$ \\
\hline & $\left(+5.933 \times 10^{-3}\right)$ & & & & & \\
\hline$+2.960 \times 10^{-2}$ & & & $-1.407 \times 10^{-3}$ & & & $0.00015(0.00013)$ \\
\hline$\left(+2.982 \times 10^{-2}\right)$ & & & $\left(-1.518 \times 10^{-3}\right)$ & & & \\
\hline$+3.971 \times 10^{-2}$ & $-2.173 \times 10^{-3}$ & & $-1.073 \times 10^{-2}$ & $+1.804 \times 10^{-3}$ & & $0.00019(0.00018)$ \\
\hline$\left(+4.033 \times 10^{-2}\right)$ & $\left(-2.299 \times 10^{-3}\right)$ & & $\left(-1.029 \times 10^{-2}\right)$ & $\left(+1.682 \times 10^{-3}\right)$ & & \\
\hline$+3.519 \times 10^{-2}$ & & $-2.452 \times 10^{-4}$ & $-1.073 \times 10^{-2}$ & $+1.804 \times 10^{-3}$ & & $0.00020(0.00020)$ \\
\hline$\left(+3.573 \times 10^{-2}\right)$ & & $\left(-2.63 \times 10^{-4}\right)$ & $\left(-1.031 \times 10^{-2}\right)$ & $\left(+1.684 \times 10^{-3}\right)$ & & \\
\hline
\end{tabular}

${ }^{\mathrm{a}}$ Units: $b_{01}, \mathrm{~kg} \cdot \mathrm{mol}^{-1} ; b_{02}$ and $b_{12}, \mathrm{~kg}^{2} \cdot \mathrm{mol}^{-2} ; b_{03}, b_{13}$, and $b_{23}, \mathrm{~kg}^{3} \cdot \mathrm{mol}^{-3} \cdot \operatorname{RMSE}(\phi)$ and $\operatorname{RMSE}(f)$ (given in parentheses) denote the root-mean-square error in the osmotic coefficient and in $\Delta f$, respectively, resulting from the parameter conversion step only; their values do not include errors from the six-parameter source model. Each set of derived parameters is followed by the reported set [16] (given in parentheses) that was obtained by direct least-squares analysis of the experimental osmotic coefficients ${ }^{\mathrm{b}}$ Source model parameters and $\operatorname{RMSE}(\phi)$ from direct fit to experimental osmotic coefficients 
Table 4 Parameters for Scatchard's neutral-electrolyte model for $\mathrm{NaCl}+\mathrm{MgCl}_{2}+\mathrm{H}_{2} \mathrm{O}$ at $298.15 \mathrm{~K}$ based on the six-parameter source model with $I \leq 9.873 \mathrm{~mol} \cdot \mathrm{kg}^{-1}$ [16] and various models with a reduced number of model parameters ${ }^{\text {a }}$

\begin{tabular}{|c|c|c|c|c|c|c|}
\hline$b_{01}$ & $b_{02}$ & $b_{03}$ & $b_{12}$ & $b_{13}$ & $b_{23}$ & $\begin{array}{l}\operatorname{RMSE}(\phi) \\
\text { and } \\
\operatorname{RMSE}(f)\end{array}$ \\
\hline$+2.713 \times 10^{-2}$ & & & & & & $0.00135(0.00129)$ \\
\hline \multicolumn{7}{|l|}{$\left(+2.902 \times 10^{-2}\right)$} \\
\hline$+3.299 \times 10^{-2}$ & $-0.792 \times 10^{-3}$ & & & & & $0.00053(0.00050)$ \\
\hline$\left(3.5768 \times 10^{-2}\right)$ & $\left(-1.110 \times 10^{-3}\right)$ & & & & & \\
\hline$+4.697 \times 10^{-2}$ & $-5.512 \times 10^{-3}$ & $+3.586 \times 10^{-4}$ & & & & $0.00200(0.00191)$ \\
\hline$\left(+5.021 \times 10^{-2}\right)$ & $\left(-6.856 \times 10^{-3}\right)$ & $\left(+5.14 \times 10^{-4}\right)$ & & & & \\
\hline$+4.697 \times 10^{-2}$ & $-5.512 \times 10^{-3}$ & $+3.586 \times 10^{-4}$ & $-1.257 \times 10^{-4}$ & & & $0.00392(0.00417)$ \\
\hline$\left(+4.405 \times 10^{-2}\right)$ & $\left(-3.607 \times 10^{-3}\right)$ & $\left(+1.15 \times 10^{-4}\right)$ & $\left(-1.705 \times 10^{-3}\right)$ & & & \\
\hline$+4.697 \times 10^{-2}$ & $-5.512 \times 10^{-3}$ & $+3.586 \times 10^{-4}$ & $-4.774 \times 10^{-3}$ & $+5.650 \times 10^{-4}$ & & $0.00281(0.00297)$ \\
\hline$\left(+4.614 \times 10^{-2}\right)$ & $\left(-4.793 \times 10^{-3}\right)$ & $\left(+2.52 \times 10^{-4}\right)$ & $\left(-3.009 \times 10^{-3}\right)$ & $\left(+2.05 \times 10^{-4}\right)$ & & \\
\hline \multirow[t]{3}{*}{$\left(+4.697 \times 10^{-2}\right)^{b}$} & $\left(-5.512 \times 10^{-3}\right)^{b}$ & $\left(+3.22 \times 10^{-4}\right)^{b}$ & $\left(-4.774 \times 10^{-3}\right)^{b}$ & $\left(+5.65 \times 10^{-4}\right)^{\mathrm{b}}$ & $\left(+2.56 \times 10^{-4}\right)^{b}$ & $0.00220^{\mathrm{b}}$ \\
\hline & $+3.385 \times 10^{-3}$ & & & & & $0.00523(0.00500)$ \\
\hline & $\left(+4.346 \times 10^{-3}\right)$ & & & & & \\
\hline$+2.713 \times 10^{-2}$ & & & $-1.257 \times 10^{-4}$ & & & $0.00202(0.00179)$ \\
\hline$\left(+2.764 \times 10^{-2}\right)$ & & & $\left(-1.018 \times 10^{-3}\right)$ & & & \\
\hline$+3.299 \times 10^{-2}$ & $-0.792 \times 10^{-3}$ & & $-1.257 \times 10^{-4}$ & & & $0.00431(0.00462)$ \\
\hline$\left(+4.107 \times 10^{-2}\right)$ & $\left(-2.380 \times 10^{-3}\right)$ & & $\left(-1.790 \times 10^{-3}\right)$ & & & \\
\hline$+3.299 \times 10^{-2}$ & $-0.792 \times 10^{-3}$ & & $-4.774 \times 10^{-3}$ & $+5.650 \times 10^{-4}$ & & $0.00432(0.00468)$ \\
\hline$\left(+4.074 \times 10^{-2}\right)$ & $\left(-2.319 \times 10^{-3}\right)$ & & $\left(-2.108 \times 10^{-3}\right)$ & $\left(+0.46 \times 10^{-4}\right)$ & & \\
\hline$+3.446 \times 10^{-2}$ & $-1.287 \times 10^{-3}$ & & $-1.257 \times 10^{-4}$ & & $+2.635 \times 10^{-4}$ & $0.00382(0.00425)$ \\
\hline$\left(+4.183 \times 10^{-2}\right)$ & $\left(-2.601 \times 10^{-3}\right)$ & & $\left(-1.472 \times 10^{-3}\right)$ & & $\left(+1.23 \times 10^{-4}\right)$ & \\
\hline$+3.446 \times 10^{-2}$ & $-1.287 \times 10^{-3}$ & & $-4.774 \times 10^{-3}$ & $+5.650 \times 10^{-4}$ & $+2.635 \times 10^{-4}$ & $0.00240(0.00260)$ \\
\hline$\left(+4.013 \times 10^{-2}\right)$ & $\left(-2.352 \times 10^{-3}\right)$ & & $\left(-3.497 \times 10^{-3}\right)$ & $\left(+3.37 \times 10^{-4}\right)$ & $\left(+2.34 \times 10^{-4}\right)$ & \\
\hline$+2.997 \times 10^{-2}$ & & $-8.510 \times 10^{-5}$ & $-4.774 \times 10^{-3}$ & $+5.650 \times 10^{-4}$ & $2.560 \times 10^{-4}$ & $0.00369(0.00400)$ \\
\hline$\left(+3.426 \times 10^{-2}\right)$ & & $\left(-2.16 \times 10^{-4}\right)$ & $\left(-2.838 \times 10^{-3}\right)$ & $\left(+2.20 \times 10^{-4}\right)$ & $\left(+2.18 \times 10^{-4}\right)$ & \\
\hline
\end{tabular}

${ }^{\mathrm{a}}$ Units: $b_{01}, \mathrm{~kg} \cdot \mathrm{mol}^{-1} ; b_{02}$ and $b_{12}, \mathrm{~kg}^{2} \cdot \mathrm{mol}^{-2} ; b_{03}, b_{13}$, and $b_{23}, \mathrm{~kg}^{3} \cdot \mathrm{mol}^{-3} \cdot \operatorname{RMSE}(\phi)$ and $\operatorname{RMSE}(f)$ (given in parentheses) denote the root-mean-square error in the osmotic coefficient and in $\Delta f$, respectively, resulting from the parameter conversion step only; their values do not include errors from the six-parameter source model. Each set of derived parameters is followed by the reported set [16] (given in parentheses) that was obtained by direct least-squares analysis of the experimental osmotic coefficients ${ }^{\mathrm{b}}$ Source model parameters and $\operatorname{RMSE}(\phi)$ from direct fit to experimental osmotic coefficients 
Table 5 Parameters for Scatchard's neutral-electrolyte model for $\mathrm{MgCl}_{2}+\mathrm{MgSO}_{4}+\mathrm{H}_{2} \mathrm{O}$ at $298.15 \mathrm{~K}$ based on the six-parameter source model with $I \leq 9.432 \mathrm{~mol} \cdot \mathrm{kg}^{-1}$ [12] and various models with a reduced number of model parameters ${ }^{\text {a }}$

\begin{tabular}{|c|c|c|c|c|c|c|}
\hline$b_{01}$ & $b_{02}$ & $b_{03}$ & $b_{12}$ & $b_{13}$ & $b_{23}$ & $\begin{array}{l}\operatorname{RMSE}(\phi) \\
\text { and } \\
\operatorname{RMSE}(f)\end{array}$ \\
\hline$-4.400 \times 10^{-2}$ & & & & & & $0.00528(0.00506)$ \\
\hline \multicolumn{7}{|l|}{$\left(-4.011 \times 10^{-2}\right)$} \\
\hline$-2.717 \times 10^{-2}$ & $-2.379 \times 10^{-3}$ & & & & & $0.00443(0.00425)$ \\
\hline$\left(-3.354 \times 10^{-2}\right)$ & $\left(-1.145 \times 10^{-3}\right)$ & & & & & \\
\hline$-3.341 \times 10^{-2}$ & & $-1.983 \times 10^{-4}$ & & & & $0.00398(0.00381)$ \\
\hline \multirow[t]{3}{*}{$\left(-3.584 \times 10^{-2}\right)$} & & $\left(-1.128 \times 10^{-4}\right)$ & & & & \\
\hline & $-1.037 \times 10^{-2}$ & $+5.585 \times 10^{-4}$ & & & & $0.00410(0.00392)$ \\
\hline & $\left(-1.212 \times 10^{-2}\right)$ & $\left(+8.116 \times 10^{-4}\right)$ & & & & \\
\hline$-4.561 \times 10^{-2}$ & $+4.138 \times 10^{-3}$ & $-5.182 \times 10^{-4}$ & & & & $0.00389(0.00372)$ \\
\hline$\left(-4.532 \times 10^{-2}\right)$ & $\left(+3.625 \times 10^{-3}\right)$ & $\left(-4.111 \times 10^{-4}\right)$ & & & & \\
\hline$-2.717 \times 10^{-2}$ & $-2.379 \times 10^{-3}$ & & $-1.229 \times 10^{-3}$ & & & $0.00507(0.00538)$ \\
\hline$\left(-3.311 \times 10^{-2}\right)$ & $\left(-1.261 \times 10^{-3}\right)$ & & $\left(-1.428 \times 10^{-4}\right)$ & & & \\
\hline$\left(-4.561 \times 10^{-2}\right)^{b}$ & $\left(+4.138 \times 10^{-3}\right)^{b}$ & $\left(-4.953 \times 10^{-4}\right)^{b}$ & $\left(-4.894 \times 10^{-4}\right)^{b}$ & $\left(-9.412 \times 10^{-5}\right)^{b}$ & $\left(-1.603 \times 10^{-4}\right)^{b}$ & $0.0015^{b}$ \\
\hline
\end{tabular}

${ }^{\mathrm{a}}$ Units: $b_{01}, \mathrm{~kg} \cdot \mathrm{mol}^{-1} ; b_{02}$ and $b_{12}, \mathrm{~kg}^{2} \cdot \mathrm{mol}^{-2} ; b_{03}, b_{13}$, and $b_{23}, \mathrm{~kg}^{3} \cdot \mathrm{mol}^{-3} \cdot \operatorname{RMSE}(\phi)$ and $\operatorname{RMSE}(f)$ (given in parentheses) denote the root-mean-square error in the osmotic coefficient and in $\Delta f$, respectively, resulting from the parameter conversion step only; their values do not include errors from the six-parameter source model. Each set of derived parameters is followed by the reported set [12] (given in parentheses) that was obtained by direct least-squares analysis of the experimental osmotic coefficients ${ }^{\mathrm{b}}$ Source model parameters and $\operatorname{RMSE}(\phi)$ from direct fit to experimental osmotic coefficients 
Table 6 Ionic strengths for the highest molalities of the isopiestic experiments for the $\mathrm{NaCl}+\mathrm{SrCl}_{2}+\mathrm{H}_{2} \mathrm{O}, \mathrm{NaCl}+\mathrm{MgCl}_{2}+\mathrm{H}_{2} \mathrm{O}$, and $\mathrm{MgCl}_{2}+\mathrm{MgSO}_{4}+\mathrm{H}_{2} \mathrm{O}$ systems at $298.15 \mathrm{~K}$ as a function of $y_{1}{ }^{\mathrm{a}}$

\begin{tabular}{llll}
\hline$y_{1}$ & $\begin{array}{l}\mathrm{NaCl}+\mathrm{SrCl}_{2}+\mathrm{H}_{2} \mathrm{O} \\
I_{\max } / \mathrm{mol}^{-1} \mathrm{~kg}^{-1}\end{array}$ & $\begin{array}{l}\mathrm{NaCl}+\mathrm{MgCl}_{2}+\mathrm{H}_{2} \mathrm{O} \\
I_{\max } / \mathrm{mol} \cdot \mathrm{kg}^{-1}\end{array}$ & $\begin{array}{l}\mathrm{MgCl}_{2}+\mathrm{MgSO}_{4}+\mathrm{H}_{2} \mathrm{O} \\
I_{\max } / \mathrm{mol}^{-} \mathrm{kg}^{-1}\end{array}$ \\
\hline 0.1 & 12.4 & 10.5 & 10.8 \\
0.2 & 10.8 & 9.4 & $9.4^{\mathrm{b}}$ \\
0.3 & 9.6 & 8.5 & 8.4 \\
0.4 & 8.8 & 8.0 & $7.4^{\mathrm{b}}$ \\
0.5 & 8.2 & 7.6 & 6.7 \\
0.6 & 7.6 & 7.3 & $6.1^{\mathrm{b}}$ \\
0.7 & 7.2 & 7.0 & 5.6 \\
0.8 & 6.8 & 6.7 & $5.3^{\mathrm{b}}$ \\
0.9 & 6.5 & 6.4 & 4.9 \\
\hline
\end{tabular}

${ }^{\mathrm{a}}$ These values of $I_{\max }$ were obtained by graphical smoothing of the ionic strengths for the highest molality isopiestic experiments $[12,15,16]$. Because of the rapid change of $I_{\max }$ with $y_{1}$, the smoothed values are uncertain by ca. $0.2 \mathrm{~mol} \cdot \mathrm{kg}^{-1}$

$\mathrm{b}$ These four values are reliable to the reported number of figures because the isopiestic experiments were performed at these ionic strength fractions 
Table 7 Root mean square errors in the osmotic coefficient $\operatorname{RMSE}(\Delta \phi)$ from converting the full parameter source models to models with fewer parameters for the $\mathrm{NaCl}+\mathrm{SrCl}_{2}+$ $\mathrm{H}_{2} \mathrm{O}, \mathrm{NaCl}+\mathrm{MgCl}_{2}+\mathrm{H}_{2} \mathrm{O}$, and $\mathrm{MgCl}_{2}+\mathrm{MgSO}_{4}+\mathrm{H}_{2} \mathrm{O}$ systems at $298.15 \mathrm{~K}^{\mathrm{a}}$

\begin{tabular}{|c|c|c|c|c|c|}
\hline Parameters & $\begin{array}{l}\text { System } 1 \\
\operatorname{RMSE}(\Delta \phi)\end{array}$ & $\begin{array}{l}\text { System } 2 \\
\operatorname{RMSE}(\Delta \phi)\end{array}$ & $\begin{array}{l}\text { System } 3 \\
\operatorname{RMSE}(\Delta \phi)\end{array}$ & $\begin{array}{l}\text { System } 4 \\
\operatorname{RMSE}(\Delta \phi)\end{array}$ & $\begin{array}{l}\text { System } 5 \\
\operatorname{RMSE}(\Delta \phi)\end{array}$ \\
\hline$b_{01}$ & 0.00203 & 0.01142 & 0.00233 & 0.00308 & 0.00772 \\
\hline$b_{01}, b_{02}$ & 0.00142 & 0.00550 & 0.00189 & 0.00277 & 0.00538 \\
\hline$b_{01}, b_{02}, b_{03}$ & 0.00123 & 0.00502 & 0.00188 & 0.00262 & 0.00466 \\
\hline$b_{01}, b_{02}, b_{03}, b_{12}$ & 0.00020 & 0.00039 & 0.00137 & 0.00255 & \\
\hline$b_{01}, b_{02}, b_{03}, b_{12}, b_{13}$ & source & source & 0.00044 & 0.00201 & \\
\hline$b_{01}, b_{02}, b_{03}, b_{12}$ & & & source & source & source \\
\hline \multicolumn{6}{|l|}{$b_{13}, b_{23}$} \\
\hline$b_{01}, b_{12}$ & 0.00170 & 0.01058 & 0.00198 & 0.00303 & \\
\hline \multicolumn{6}{|l|}{$b_{01}, b_{12}, b_{13}$} \\
\hline$b_{01}, b_{02}, b_{12}$ & 0.00073 & 0.00229 & & 0.00270 & 0.00349 \\
\hline$b_{01}, b_{02}, b_{12}, b_{13}$ & 0.00068 & & 0.00056 & 0.00228 & \\
\hline$b_{01}, b_{02}, b_{12}, b_{23}$ & & & & 0.00185 & \\
\hline$b_{01}, b_{02}, b_{12}, b_{13}, b_{23}$ & & & & 0.00097 & \\
\hline$b_{02}$ & 0.00260 & & 0.00509 & 0.00681 & \\
\hline$b_{02}, b_{03}$ & 0.00126 & 0.00508 & & & 0.00775 \\
\hline$b_{02}, b_{12}, b_{13}$ & 0.00224 & 0.00075 & & & \\
\hline$b_{01}, b_{03}$ & & & & & 0.00497 \\
\hline$b_{01}, b_{03}, b_{12}, b_{13}$ & & & 0.00070 & & \\
\hline$b_{01}, b_{03}, b_{12}, b_{13}, b_{23}$ & & & & 0.00125 & \\
\hline$b_{02}, b_{03}, b_{12}$ & 0.00031 & & & & \\
\hline$b_{02}, b_{03}, b_{12}, b_{13}$ & 0.00023 & & & & \\
\hline
\end{tabular}

${ }^{\text {a }}$ System 1: $\mathrm{NaCl}+\mathrm{SrCl}_{2}+\mathrm{H}_{2} \mathrm{O}$ with $I \leq 6.16 \mathrm{~mol} \cdot \mathrm{kg}^{-1}$ and Table 1 converted parameters. System 2: $\mathrm{NaCl}+\mathrm{SrCl}_{2}+\mathrm{H}_{2} \mathrm{O}$ with $I \leq 11.2 \mathrm{~mol} \cdot \mathrm{kg}^{-1}$ and Table 2 converted parameters. System 3: $\mathrm{NaCl}+\mathrm{MgCl}_{2}+\mathrm{H}_{2} \mathrm{O}$ with $I \leq 6.2 \mathrm{~mol} \cdot \mathrm{kg}^{-1}$ and Table 3 converted parameters. System 4: $\mathrm{NaCl}+\mathrm{MgCl}_{2}+\mathrm{H}_{2} \mathrm{O}$ with $I \leq 9.873 \mathrm{~mol} \cdot \mathrm{kg}^{-1}$ and Table 4 converted parameters. System 5: $\mathrm{MgCl}_{2}+\mathrm{MgSO}_{4}+\mathrm{H}_{2} \mathrm{O}$ with $I \leq 9.432 \mathrm{~mol} \cdot \mathrm{kg}^{-1}$ and Table 5 converted parameters 


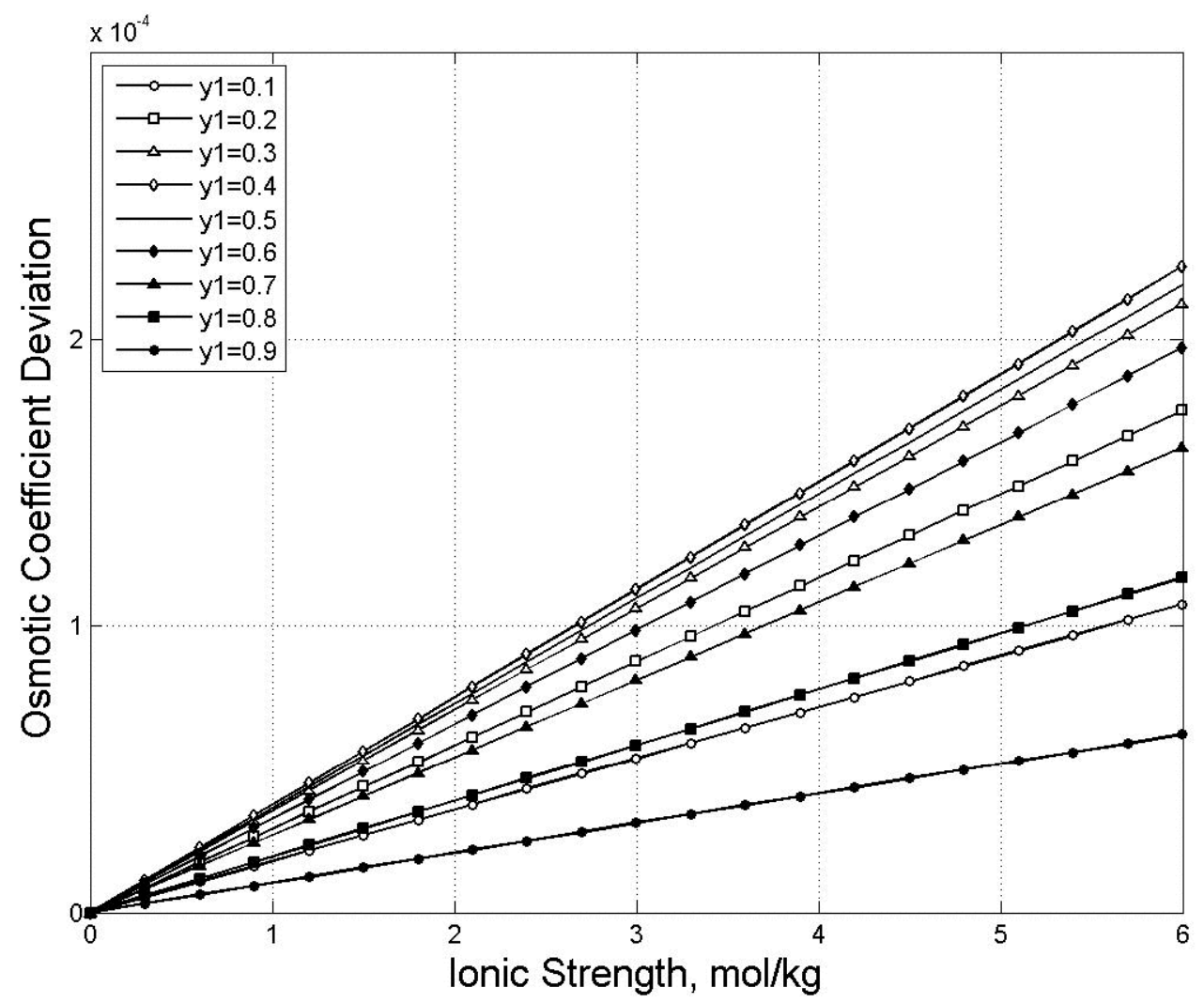

Fig 1 Differences between values of the osmotic coefficients calculated with the $\left\{b_{01}\right.$; Table 1$\}$ converted parameter set and the corresponding set obtained directly by leastsquares analysis of the experimental source data as a function of the ionic strength, at $y_{1}=$ (0.1. 0.2, 0.3, 0.4, 0.5, 0.6, 0.7, 0.8, and 0.9), for $\mathrm{NaCl}+\mathrm{SrCl}_{2}+\mathrm{H}_{2} \mathrm{O}$ with $I_{\max } \leq 6.16$ $\mathrm{mol} \cdot \mathrm{kg}^{-1}$ 


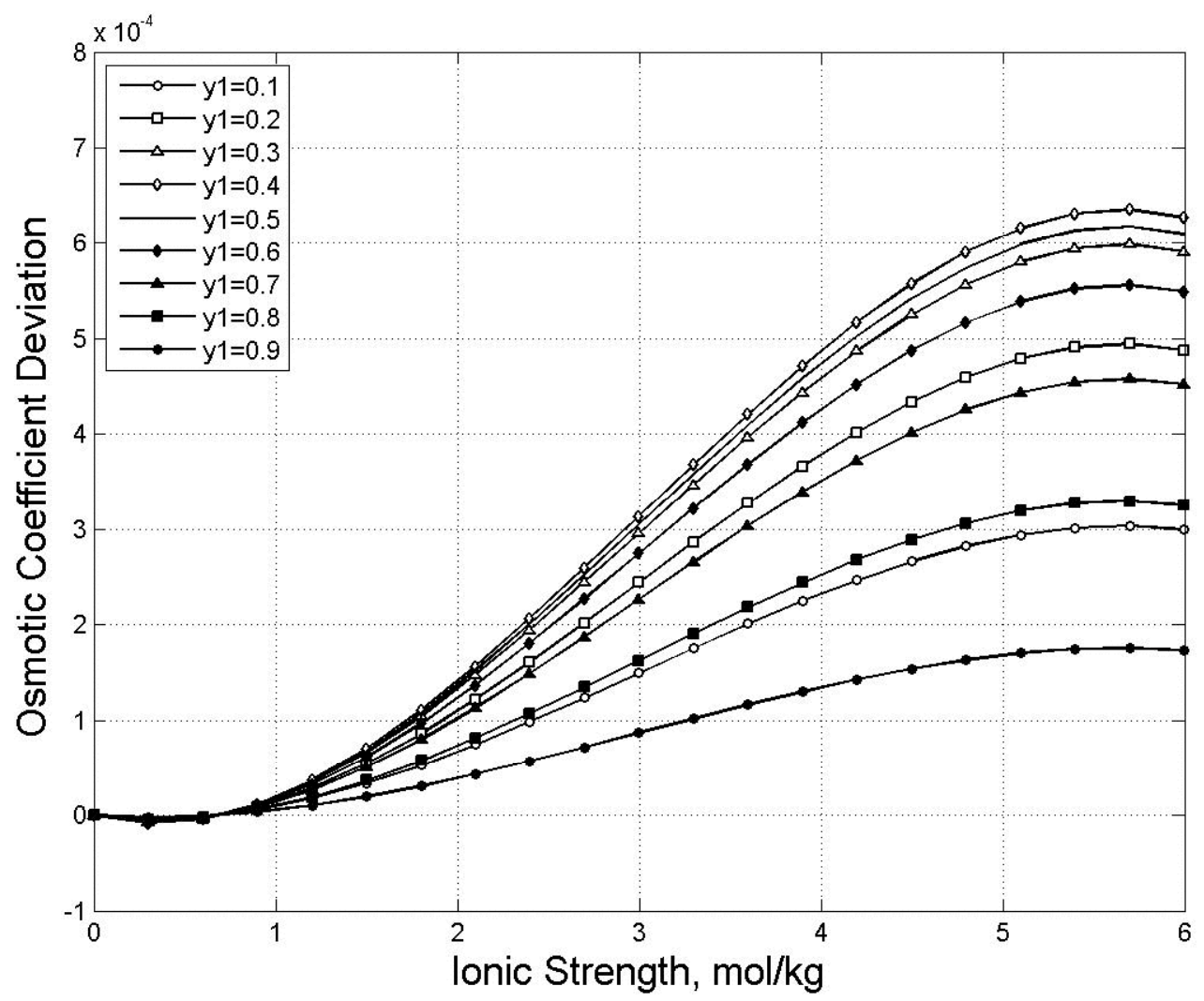

Fig 2 Differences between values of the osmotic coefficients calculated with the $\left\{b_{01}, b_{02}\right.$, $b_{03}$; Table 1 \} converted parameter set and the corresponding set obtained directly by least-squares analysis of the experimental source data as a function of the ionic strength, at $y_{1}=\left(0.1\right.$. 0.2, 0.3, 0.4, 0.5, 0.6, 0.7, 0.8, and 0.9), for $\mathrm{NaCl}+\mathrm{SrCl}_{2}+\mathrm{H}_{2} \mathrm{O}$ with $I_{\max } \leq$ $6.16 \mathrm{~mol} \cdot \mathrm{kg}^{-1}$ 


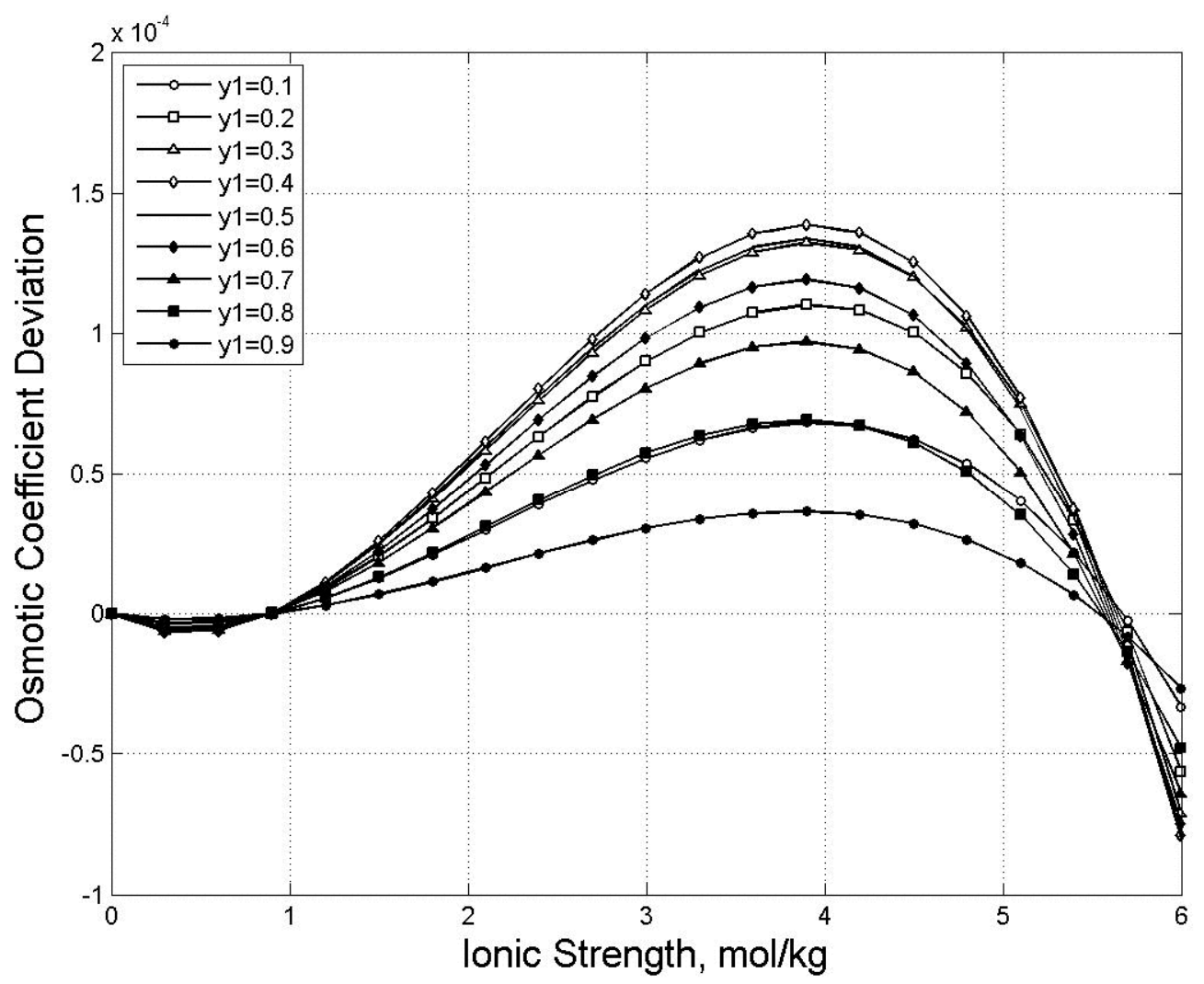

Fig 3 Differences between values of the osmotic coefficients calculated with the $\left\{b_{01}, b_{02}\right.$, $b_{03}, b_{12}$; Table 1$\}$ converted parameter set and the corresponding set obtained directly by least-squares analysis of the experimental source data as a function of the ionic strength, at $y_{1}=\left(0.1\right.$. 0.2, 0.3, 0.4, 0.5, 0.6, 0.7, 0.8, and 0.9), for $\mathrm{NaCl}+\mathrm{SrCl}_{2}+\mathrm{H}_{2} \mathrm{O}$ with $I_{\max } \leq$ $6.16 \mathrm{~mol} \cdot \mathrm{kg}^{-1}$ 


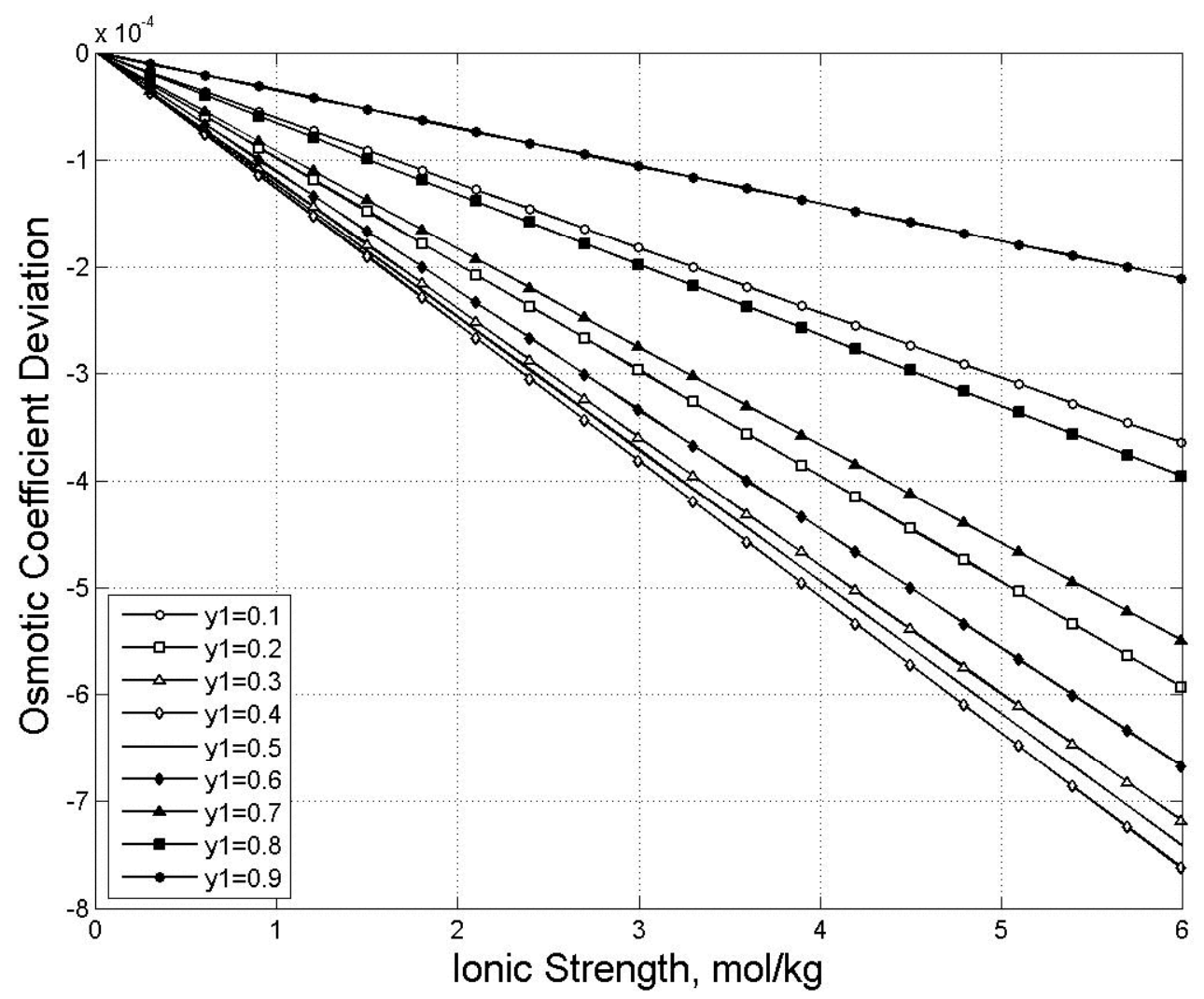

Fig 4 Differences between values of the osmotic coefficients calculated with the $\left\{b_{01}\right.$;

Table 3$\}$ converted parameter set and the corresponding set obtained directly by leastsquares analysis of the experimental source data as a function of the ionic strength, at $y_{1}=$ (0.1. 0.2, 0.3, 0.4, 0.5, 0.6, 0.7, 0.8, and 0.9), for $\mathrm{NaCl}+\mathrm{MgCl}_{2}+\mathrm{H}_{2} \mathrm{O}$ with $I_{\max } \leq 6.2$ $\mathrm{mol} \cdot \mathrm{kg}^{-1}$ 


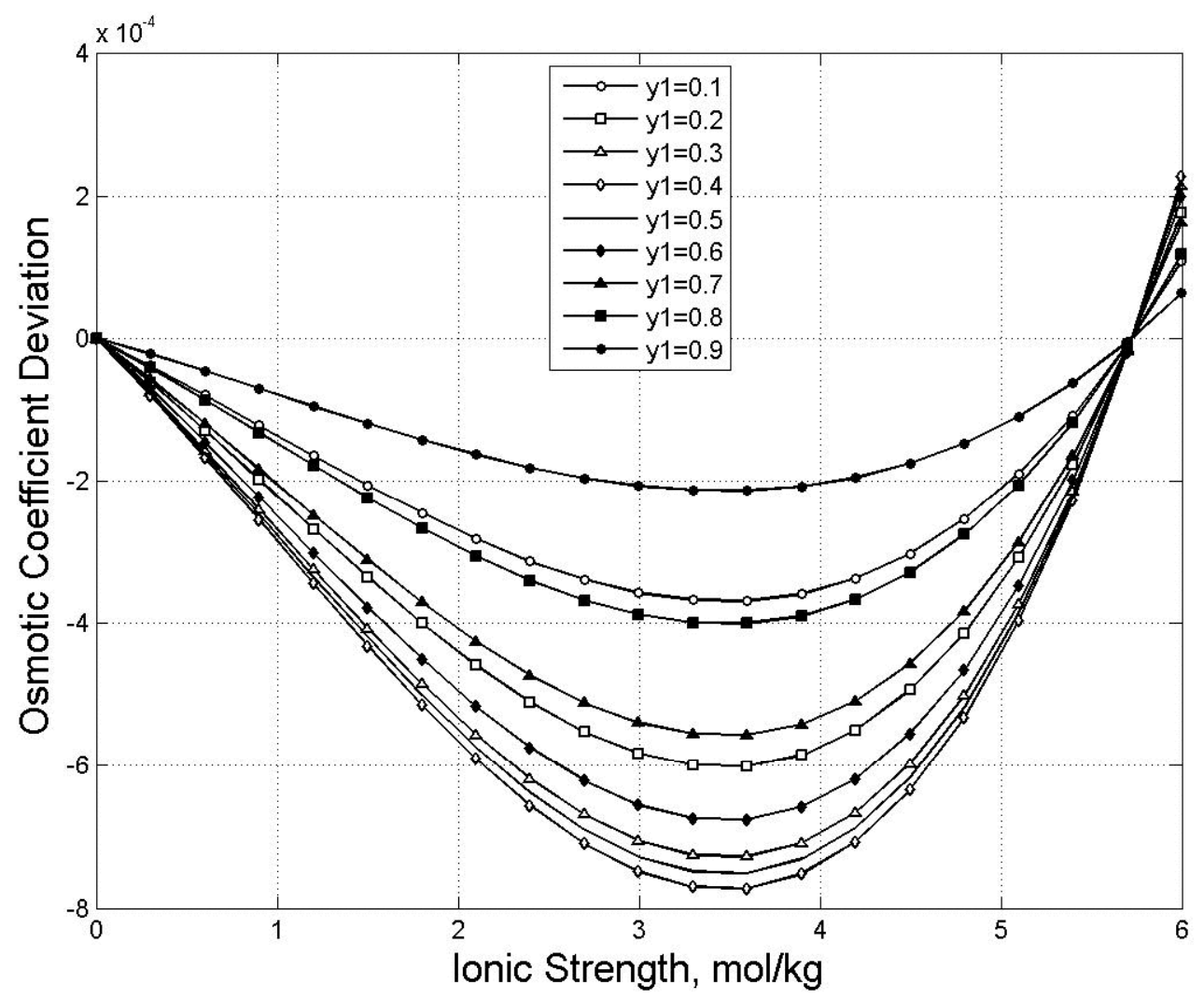

Fig 5 Differences between values of the osmotic coefficients calculated with the $\left\{b_{01}, b_{02}\right.$, $b_{03}$; Table 3 \} converted parameter set and the corresponding set obtained directly by least-squares analysis of the experimental source data as a function of the ionic strength, at $y_{1}=\left(0.1\right.$. 0.2, 0.3, 0.4, 0.5, 0.6, 0.7, 0.8, and 0.9), for $\mathrm{NaCl}+\mathrm{MgCl}_{2}+\mathrm{H}_{2} \mathrm{O}$ with $I_{\max } \leq$ $6.2 \mathrm{~mol} \cdot \mathrm{kg}^{-1}$ 


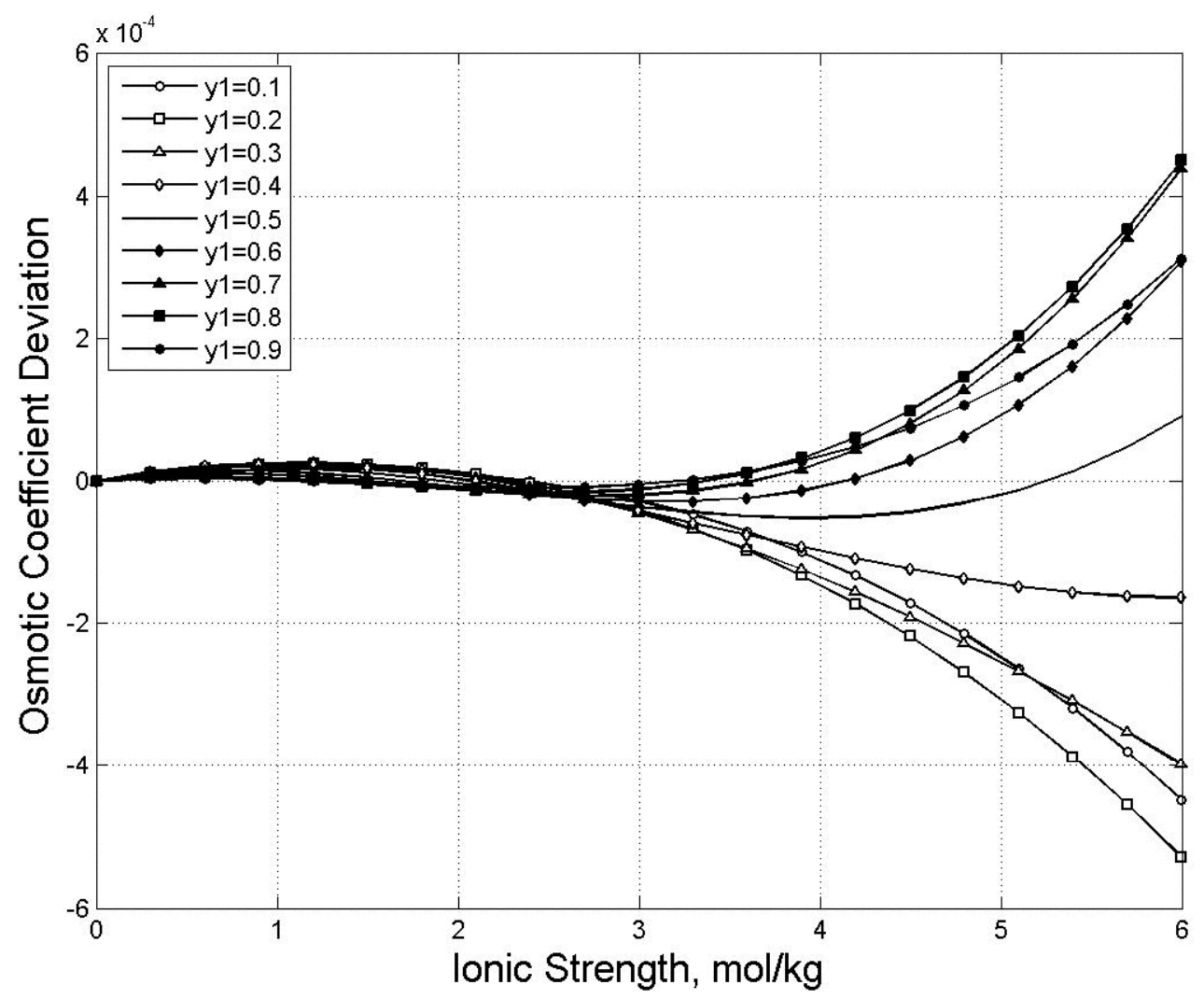

Fig 6 Differences between values of the osmotic coefficients calculated with the $\left\{b_{01}, b_{02}\right.$, $b_{03}, b_{12}, b_{13}$; Table 3 \} converted parameter set and the corresponding set obtained directly by least-squares analysis of the experimental source data as a function of the ionic strength, at $y_{1}=(0.1 .0 .2,0.3,0.4,0.5,0.6,0.7,0.8$, and 0.9$)$, for $\mathrm{NaCl}+\mathrm{MgCl}_{2}+\mathrm{H}_{2} \mathrm{O}$ with $I_{\max } \leq 6.2 \mathrm{~mol} \cdot \mathrm{kg}^{-1}$ 


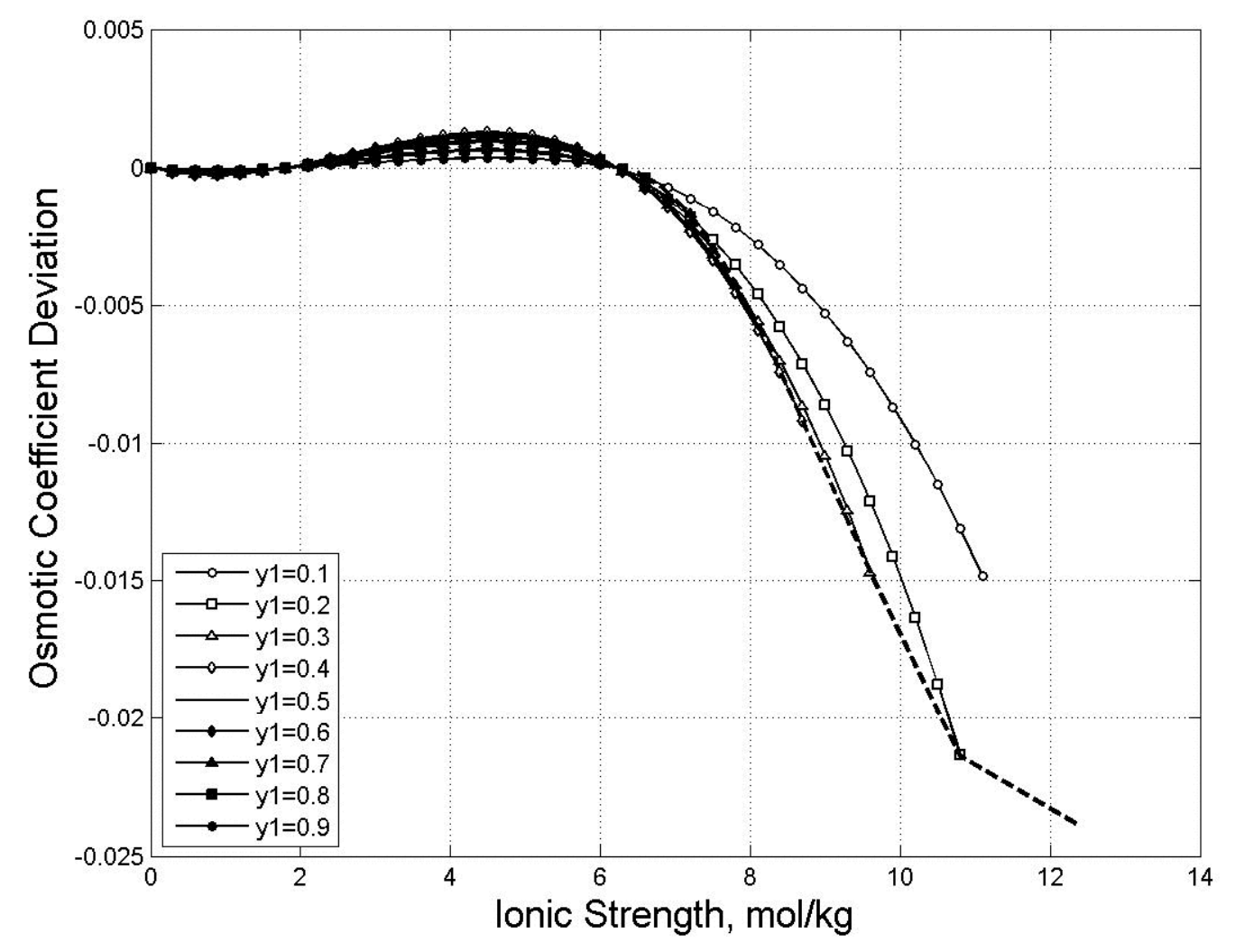

Fig 7 Differences between values of the osmotic coefficients calculated with the $\left\{b_{01}, b_{02}\right.$, $b_{03}$; Table 2 \} converted parameter set and the corresponding set obtained directly by least-squares analysis of the experimental source data as a function of the ionic strength, at $y_{1}=\left(0.1\right.$. 0.2, 0.3, 0.4, 0.5, 0.6, 0.7, 0.8, and 0.9), for $\mathrm{NaCl}+\mathrm{SrCl}_{2}+\mathrm{H}_{2} \mathrm{O}$ with $I_{\max } \leq$ $11.2 \mathrm{~mol} \cdot \mathrm{kg}^{-1}$. The dashed curve represents the $I_{\max }$ values of Table 6 


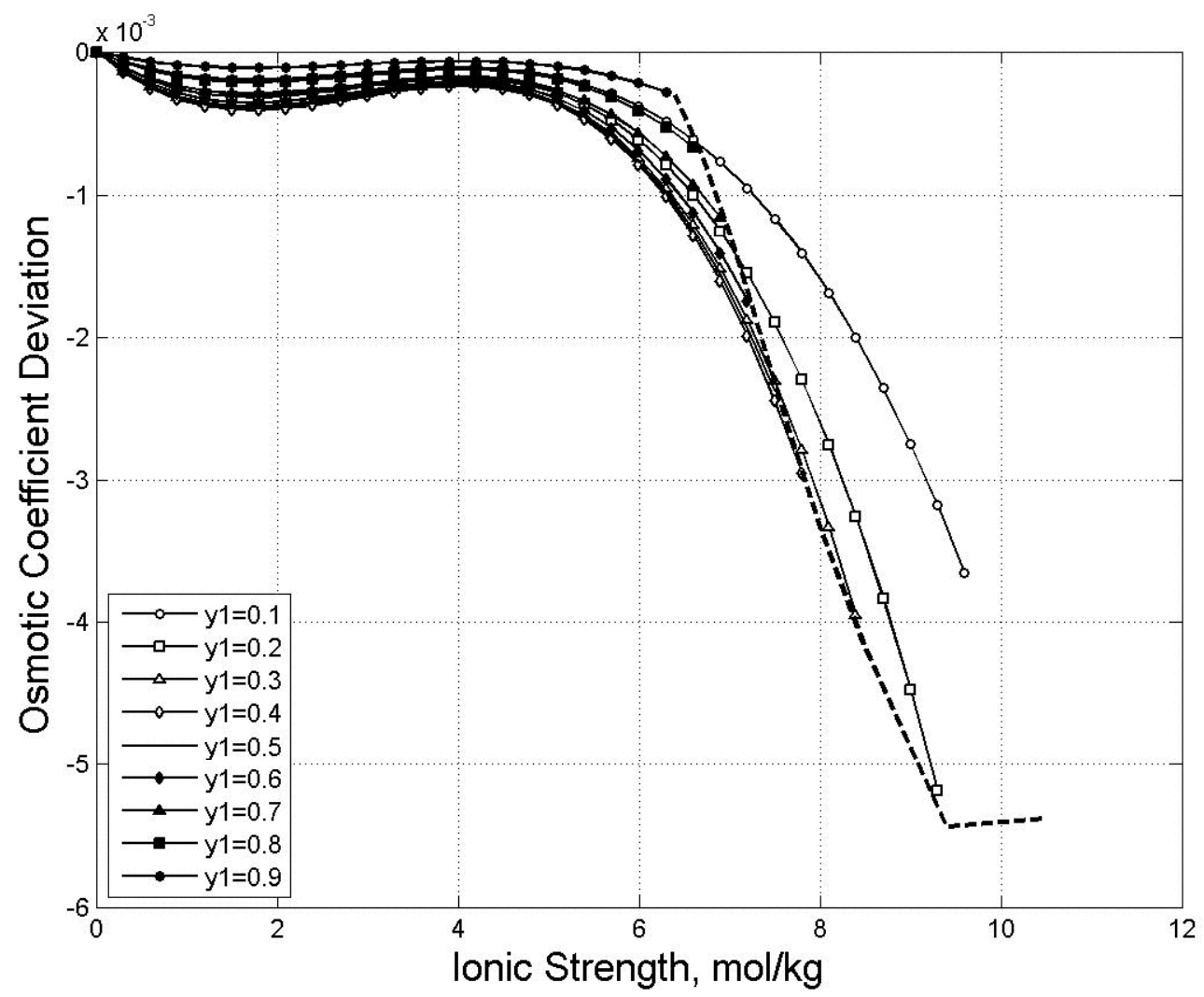

Fig 8 Differences between values of the osmotic coefficients calculated with the $\left\{b_{01}, b_{02}\right.$, $b_{03}$; Table 4$\}$ converted parameter set and the corresponding set obtained directly by least-squares analysis of the experimental source data as a function of the ionic strength, at $y_{1}=\left(0.1\right.$. 0.2, 0.3, 0.4, 0.5, 0.6, 0.7, 0.8, and 0.9), for $\mathrm{NaCl}+\mathrm{MgCl}_{2}+\mathrm{H}_{2} \mathrm{O}$ with $I_{\max } \leq$ $9.873 \mathrm{~mol} \cdot \mathrm{kg}^{-1}$. The dashed curve represents the $I_{\max }$ values of Table 6 


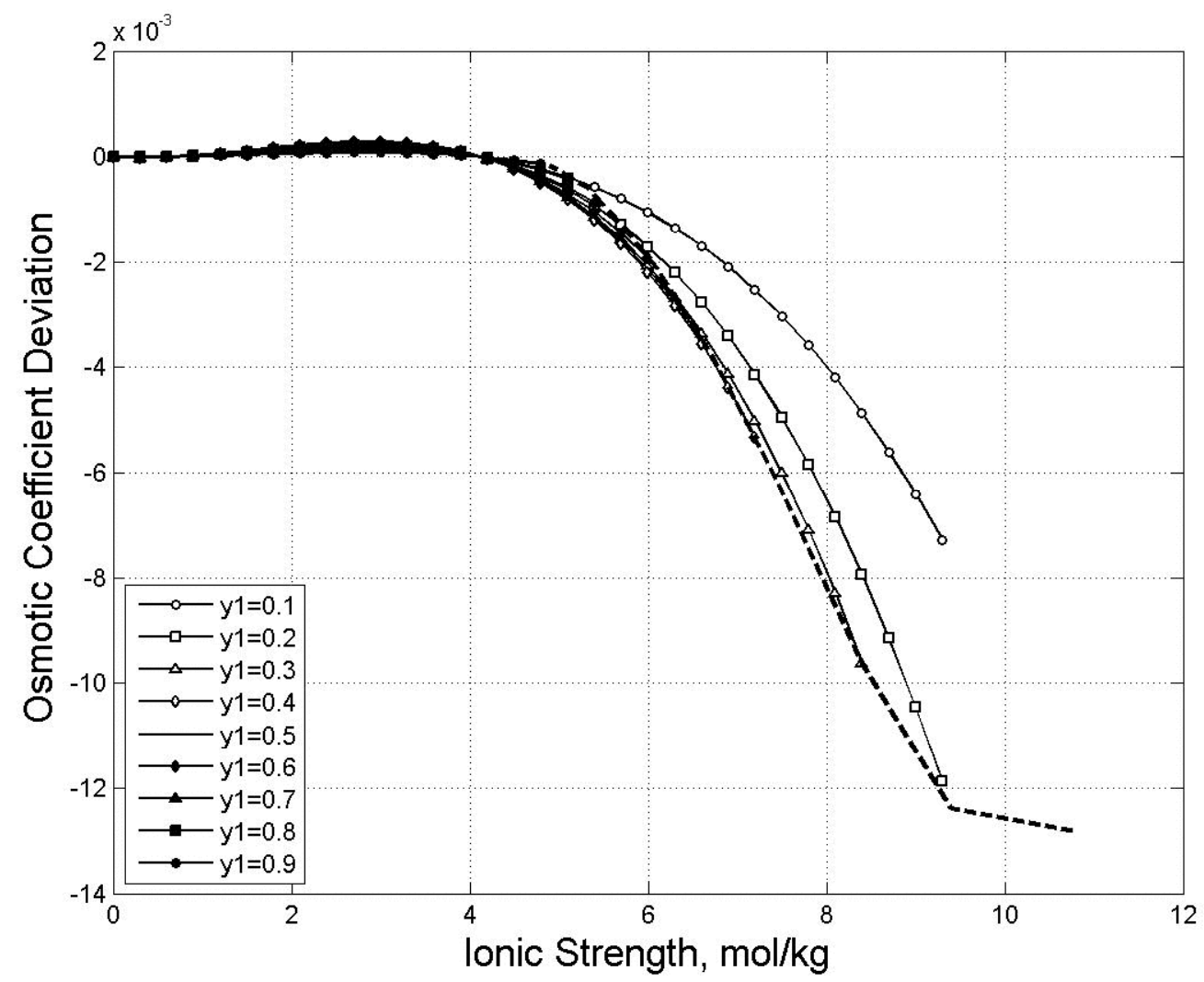

Fig 9 Differences between values of the osmotic coefficients calculated with the $\left\{b_{01}, b_{02}\right.$, $b_{03}$; Table 5$\}$ converted parameter set and the corresponding set obtained directly by least-squares analysis of the experimental source data as a function of the ionic strength, at $y_{1}=\left(0.1\right.$. 0.2, 0.3, 0.4, 0.5, 0.6, 0.7, 0.8, and 0.9), for $\mathrm{MgCl}_{2}+\mathrm{MgSO}_{4}+\mathrm{H}_{2} \mathrm{O}$ with $I_{\max }$ $\leq 9.432 \mathrm{~mol} \cdot \mathrm{kg}^{-1}$. The dashed curve represents the $I_{\max }$ values of Table 6 
Appendix A Evaluation of the partial derivatives appearing in Eqs. 21a and 21b where $\Delta f(\phi)$ is defined by Eq. 18

$$
\begin{aligned}
& \frac{\partial \Delta f(\phi)}{\partial b_{01}^{\mathrm{t}}}=\left(y_{1}-y_{1}{ }^{2}\right) I=-\frac{\partial \Delta f(\phi)}{\partial b_{01}} \\
& \frac{\partial \Delta f(\phi)}{\partial b_{02}^{\mathrm{t}}}=\left(y_{1}-y_{1}{ }^{2}\right) I^{2}=-\frac{\partial \Delta f(\phi)}{\partial b_{02}} \\
& \frac{\partial \Delta f(\phi)}{\partial b_{03}^{\mathrm{t}}}=\left(y_{1}-y_{1}{ }^{2}\right) I^{3}=-\frac{\partial \Delta f(\phi)}{\partial b_{03}} \\
& \frac{\partial \Delta f(\phi)}{\partial b_{12}^{\mathrm{t}}}=\left(-y_{1}+3 y_{1}{ }^{2}-2 y_{1}{ }^{3}\right) I^{2}=-\frac{\partial \Delta f(\phi)}{\partial b_{12}} \\
& \frac{\partial \Delta f(\phi)}{\partial b_{13}^{\mathrm{t}}}=\left(-y_{1}+3 y_{1}{ }^{2}-2 y_{1}{ }^{3}\right) I^{3}=-\frac{\partial \Delta f(\phi)}{\partial b_{13}} \\
& \frac{\partial \Delta f(\phi)}{\partial b_{23}^{\mathrm{t}}}=\left(y_{1}-5 y_{1}{ }^{2}+8 y_{1}{ }^{3}-4 y_{1}{ }^{4}\right) I^{3}=-\frac{\partial \Delta f(\phi)}{\partial b_{23}}
\end{aligned}
$$


Appendix B Evaluation of the matrix elements $B_{j k}^{l m}$ when the maximum ionic strength, $I_{\max }$, does not depend on the ionic-strength fraction, $y_{1}$

First we evaluate the six diagonal matrix elements of Eq. 24, i.e., those with $j k=l m$, as defined by Eq. 26:

$$
\begin{aligned}
& B_{01,01}=-\int_{\mathrm{y}_{1}=0}^{\mathrm{y}_{1}=1} \int_{I=0}^{I_{\max }}\left(\frac{\partial \Delta f(\phi)}{\partial b_{01}^{\mathrm{t}}}\right)\left(\frac{\partial \Delta f(\phi)}{\partial b_{01}}\right) \mathrm{d} I \mathrm{~d} y_{1} \\
& =\int_{\mathrm{y}_{1}=0}^{\mathrm{y}_{1}=1} \int_{I=0}^{1 I_{\max }}\left(y_{1}-y_{1}^{2}\right)^{2} I^{2} \mathrm{~d} I \mathrm{~d} y \\
& \left.=\left(\frac{I_{\max }^{3}}{3}\right)\left(\frac{y_{1}^{3}}{3}-\frac{y_{1}^{4}}{2}+\frac{y_{1}^{5}}{5}\right)\right]_{y_{1}=0}^{y_{1}=1} \\
& =\left(\frac{I_{\max }^{3}}{3}\right)\left(\frac{1}{30}\right) \\
& =\left(\frac{I_{\max }^{3}}{90}\right) \\
& B_{02,02}=-\int_{\mathrm{y}_{1}=0}^{\mathrm{y}_{1}=1} \int_{I=0}^{I_{\max }}\left(\frac{\partial \Delta f(\phi)}{\partial b_{02}^{\mathrm{t}}}\right)\left(\frac{\partial \Delta f(\phi)}{\partial b_{02}}\right) \mathrm{d} I \mathrm{~d} y_{1} \\
& =\int_{\mathrm{y}_{1}=0}^{\mathrm{y}_{1}=1} \int_{I=0}^{I_{\max }}\left(y_{1}-y_{1}^{2}\right)^{2} I^{4} \mathrm{~d} I \mathrm{~d} y \\
& =\left(\frac{I_{\max }^{5}}{5}\right)\left(\frac{1}{30}\right) \\
& =\left(\frac{I_{\max }^{5}}{150}\right) \\
& B_{03,03}=-\int_{\mathrm{y}_{1}=0}^{\mathrm{y}_{1}=1 I_{I=0}} \int_{\max }\left(\frac{\partial \Delta f(\phi)}{\partial b_{03}^{\mathrm{t}}}\right)\left(\frac{\partial \Delta f(\phi)}{\partial b_{03}}\right) \mathrm{d} I \mathrm{~d} y_{1} \\
& =\int_{\mathrm{y}_{1}=0}^{\mathrm{y}_{1}=1 \int_{I=0} \int_{\max }}\left(y_{1}-y_{1}^{2}\right)^{2} I^{6} \mathrm{~d} I \mathrm{~d} y \\
& =\left(\frac{I_{\max }^{7}}{7}\right)\left(\frac{1}{30}\right) \\
& =\left(\frac{I_{\max }^{7}}{210}\right)
\end{aligned}
$$




$$
\begin{aligned}
& B_{12,12}=-\int_{\mathrm{y}_{1}=0}^{\mathrm{y}_{1}=1} \int_{I=0}^{I_{\max }}\left(\frac{\partial \Delta f(\phi)}{\partial b_{12}^{\mathrm{t}}}\right)\left(\frac{\partial \Delta f(\phi)}{\partial b_{12}}\right) \mathrm{d} I \mathrm{~d} y_{1} \\
& =\int_{\mathrm{y}_{1}=0}^{\mathrm{y}_{1}=1} \int_{I=0}^{1 I_{\max }}\left(-y_{1}+3 y_{1}^{2}-2 y_{1}^{3}\right)^{2} I^{4} \mathrm{~d} I \mathrm{~d} y \\
& \left.=\left(\frac{I_{\max }^{5}}{5}\right)\left(\frac{y_{1}^{3}}{3}-\frac{3 y_{1}^{4}}{2}+\frac{13 y_{1}^{5}}{5}-2 y_{1}^{6}+\frac{4 y_{1}^{7}}{7}\right)\right]_{y_{1}=0}^{y_{1}=1} \\
& =\left(\frac{I_{\max }^{5}}{5}\right)\left(\frac{1}{210}\right) \\
& =\left(\frac{I_{\max }^{5}}{1050}\right) \\
& B_{13,13}=-\int_{\mathrm{y}_{1}=0}^{\mathrm{y}_{1}=1 I_{I=0}^{I_{\max }}}\left(\frac{\partial \Delta f(\phi)}{\partial b_{13}^{\mathrm{t}}}\right)\left(\frac{\partial \Delta f(\phi)}{\partial b_{13}}\right) \mathrm{d} I \mathrm{~d} y_{1} \\
& =\int_{\mathrm{y}_{1}=0}^{\mathrm{y}_{1}=1} \int_{I=0}^{I_{\max }}\left(-y_{1}+3 y_{1}^{2}-2 y_{1}^{3}\right)^{2} I^{6} \mathrm{~d} I \mathrm{~d} y \\
& =\left(\frac{I_{\max }^{7}}{7}\right)\left(\frac{1}{210}\right) \\
& =\left(\frac{I_{\max }^{7}}{1470}\right) \\
& B_{23,23}=-\int_{\mathrm{y}_{1}=0}^{\mathrm{y}_{1}=1} \int_{I=0}^{I_{\max }}\left(\frac{\partial \Delta f(\phi)}{\partial b_{23}^{\mathrm{t}}}\right)\left(\frac{\partial \Delta f(\phi)}{\partial b_{23}}\right) \mathrm{d} I \mathrm{~d} y_{1} \\
& =\int_{\mathrm{y}_{1}=0}^{\mathrm{y}_{1}=1} \int_{I=0}^{I_{\max }}\left(y_{1}-5 y_{1}^{2}+8 y_{1}^{3}-4 y_{1}^{4}\right)^{2} I^{6} \mathrm{~d} I \mathrm{~d} y \\
& \left.=\left(\frac{I_{\max }^{7}}{7}\right)\left(\frac{y_{1}^{3}}{3}-\frac{5 y_{1}^{4}}{2}+\frac{41 y_{1}{ }^{5}}{5}-\frac{44 y_{1}{ }^{6}}{3}+\frac{104 y_{1}^{7}}{7}-8 y_{1}^{8}+\frac{16 y_{1}^{9}}{9}\right)\right]_{y_{1}=0}^{y_{1}=1} \\
& =\left(\frac{I_{\max }^{7}}{4410}\right)
\end{aligned}
$$

The 30 other non-diagonal matrix elements are now given: 


$$
\begin{aligned}
& B_{01,02}=-\int_{\mathrm{y}_{1}=0}^{\mathrm{y}_{1}=1} \int_{I=0}^{I_{\max }}\left(\frac{\partial \Delta f(\phi)}{\partial b_{01}^{\mathrm{t}}}\right)\left(\frac{\partial \Delta f(\phi)}{\partial b_{02}}\right) \mathrm{d} I \mathrm{~d} y_{1} \\
& =\int_{\mathrm{y}_{1}=0}^{\mathrm{y}_{1}=1} \int_{I=0}^{I_{\max }}\left(y_{1}^{2}-2 y_{1}^{3}+\mathrm{y}_{1}^{4}\right) I^{3} \mathrm{~d} I \mathrm{~d} y \\
& \left.=\left(\frac{I_{\max }^{4}}{4}\right)\left(\frac{y_{1}^{3}}{3}-\frac{y_{1}^{4}}{2}+\frac{y_{1}^{5}}{5}\right)\right]_{y_{1}=0}^{y_{1}=1} \\
& =\left(\frac{I_{\max }^{4}}{120}\right) \\
& B_{01,03}=-\int_{\mathrm{y}_{1}=0}^{\mathrm{y}_{1}=1 I_{I=0}} \int_{\max }\left(\frac{\partial \Delta f(\phi)}{\partial b_{01}^{\mathrm{t}}}\right)\left(\frac{\partial \Delta f(\phi)}{\partial b_{03}}\right) \mathrm{d} I \mathrm{~d} y_{1} \\
& =\int_{\mathrm{y}_{1}=0}^{\mathrm{y}_{1}=1} \int_{I=0}^{I_{\max }}\left(y_{1}^{2}-2 y_{1}^{3}+\mathrm{y}_{1}^{4}\right) I^{4} \mathrm{~d} I \mathrm{~d} y \\
& \left.=\left(\frac{I_{\max }^{5}}{5}\right)\left(\frac{y_{1}^{3}}{3}-\frac{y_{1}^{4}}{2}+\frac{y_{1}^{5}}{5}\right)\right]_{y_{1}=0}^{y_{1}=1} \\
& =\left(\frac{I_{\max }^{5}}{150}\right) \\
& B_{01,12}=-\int_{\mathrm{y}_{1}=0}^{\mathrm{y}_{1}=1} \int_{I=0}^{I_{\max }}\left(\frac{\partial \Delta f(\phi)}{\partial b_{01}^{\mathrm{t}}}\right)\left(\frac{\partial \Delta f(\phi)}{\partial b_{12}}\right) \mathrm{d} I \mathrm{~d} y_{1} \\
& =\int_{\mathrm{y}_{1}=0}^{\mathrm{y}_{1}=1} \int_{I=0}^{I_{\max }}\left(-y_{1}{ }^{2}+4 y_{1}{ }^{3}-5 \mathrm{y}_{1}{ }^{4}+2 \mathrm{y}_{1}{ }^{5}\right) I^{3} \mathrm{~d} I \mathrm{~d} y \\
& \left.=\left(\frac{I_{\max }^{4}}{4}\right)\left(-\frac{y_{1}^{3}}{3}+y_{1}^{4}-y_{1}^{5}+\frac{y_{1}^{6}}{3}\right)\right]_{y_{1}=0}^{y_{1}=1} \\
& =0 \\
& B_{01,13}=-\int_{\mathrm{y}_{1}=0}^{\mathrm{y}_{1}=1} \int_{I=0}^{I_{\max }}\left(\frac{\partial \Delta f(\phi)}{\partial b_{01}^{\mathrm{t}}}\right)\left(\frac{\partial \Delta f(\phi)}{\partial b_{13}}\right) \mathrm{d} I \mathrm{~d} y_{1} \\
& =\int_{\mathrm{y}_{1}=0}^{\mathrm{y}_{1}=1} \int_{I=0}^{I_{\max }}\left(-y_{1}{ }^{2}+4 y_{1}{ }^{3}-5 \mathrm{y}_{1}{ }^{4}+2 \mathrm{y}_{1}{ }^{5}\right) I^{4} \mathrm{~d} I \mathrm{~d} y \\
& \left.=\left(\frac{I_{\max }^{5}}{5}\right)\left(-\frac{y_{1}^{3}}{3}+y_{1}^{4}-y_{1}^{5}+\frac{y_{1}^{6}}{3}\right)\right]_{y_{1}=0}^{y_{1}=1} \\
& =0
\end{aligned}
$$




$$
\begin{aligned}
& B_{01,23}=-\int_{\mathrm{y}_{1}=0}^{\mathrm{y}_{1}=1} \int_{I=0}^{I_{\max }}\left(\frac{\partial \Delta f(\phi)}{\partial b_{01}^{\mathrm{t}}}\right)\left(\frac{\partial \Delta f(\phi)}{\partial b_{23}}\right) \mathrm{d} I \mathrm{~d} y_{1} \\
& =\int_{\mathrm{y}_{1}=0}^{\mathrm{y}_{1}=1} \int_{I=0}^{1 I_{\max }}\left(y_{1}^{2}-6 y_{1}^{3}+13 \mathrm{y}_{1}{ }^{4}-12 \mathrm{y}_{1}{ }^{5}+4 \mathrm{y}_{1}{ }^{6}\right) I^{4} \mathrm{~d} I \mathrm{~d} y \\
& \left.=\left(\frac{I_{\max }^{5}}{5}\right)\left(\frac{y_{1}^{3}}{3}-\frac{3 y_{1}{ }^{4}}{2}+\frac{13 y_{1}^{5}}{5}-2 y_{1}{ }^{6}+\frac{4 \mathrm{y}_{1}{ }^{7}}{7}\right)\right]_{y_{1}=0}^{y_{1}=1} \\
& =\left(\frac{I_{\max }^{5}}{1050}\right) \\
& B_{02,01}=-\int_{\mathrm{y}_{1}=0}^{\mathrm{y}_{1}=1} \int_{I=0}^{I_{\max }}\left(\frac{\partial \Delta f(\phi)}{\partial b_{02}^{\mathrm{t}}}\right)\left(\frac{\partial \Delta f(\phi)}{\partial b_{01}}\right) \mathrm{d} I \mathrm{~d} y_{1} \\
& =\int_{\mathrm{y}_{1}=0}^{\mathrm{y}_{1}=1} \int_{I=0}^{I_{\max }}\left(y_{1}^{2}-2 y_{1}^{3}+\mathrm{y}_{1}^{4}\right) I^{3} \mathrm{~d} I \mathrm{~d} y \\
& \left.=\left(\frac{I_{\max }^{4}}{4}\right)\left(\frac{y_{1}^{3}}{3}-\frac{y_{1}^{4}}{2}+\frac{y_{1}^{5}}{5}\right)\right]_{y_{1}=0}^{y_{1}=1} \\
& =\left(\frac{I_{\max }^{4}}{120}\right) \\
& =B_{01,02} \\
& B_{02,03}=-\int_{\mathrm{y}_{1}=0}^{\mathrm{y}_{1}=1} \int_{I=0}^{I_{\max }}\left(\frac{\partial \Delta f(\phi)}{\partial b_{02}^{\mathrm{t}}}\right)\left(\frac{\partial \Delta f(\phi)}{\partial b_{03}}\right) \mathrm{d} I \mathrm{~d} y_{1} \\
& =\int_{\mathrm{y}_{1}=0}^{\mathrm{y}_{1}=1} \int_{I=0}^{I_{\max }}\left(y_{1}^{2}-2 y_{1}^{3}+\mathrm{y}_{1}^{4}\right) I^{5} \mathrm{~d} I \mathrm{~d} y \\
& \left.=\left(\frac{I_{\max }^{6}}{6}\right)\left(\frac{y_{1}^{3}}{3}-\frac{y_{1}^{4}}{2}+\frac{y_{1}^{5}}{5}\right)\right]_{y_{1}=0}^{y_{1}=1} \\
& =\left(\frac{I_{\max }^{6}}{180}\right) \\
& B_{02,12}=-\int_{\mathrm{y}_{1}=0}^{\mathrm{y}_{1}=1} \int_{I=0}^{I_{\max }}\left(\frac{\partial \Delta f(\phi)}{\partial b_{02}^{\mathrm{t}}}\right)\left(\frac{\partial \Delta f(\phi)}{\partial b_{12}}\right) \mathrm{d} I \mathrm{~d} y_{1} \\
& =\int_{\mathrm{y}_{1}=0}^{\mathrm{y}_{1}=1 I_{I=0}} \int_{\max }^{\mathrm{I}_{1}}\left(-y_{1}^{2}+4 y_{1}^{3}-5 \mathrm{y}_{1}^{4}+2 \mathrm{y}_{1}^{5}\right) I^{4} \mathrm{~d} I \mathrm{~d} y \\
& \left.=\left(\frac{I_{\max }^{5}}{5}\right)\left(-\frac{y_{1}^{3}}{3}+y_{1}^{4}-y_{1}^{5}+\frac{y_{1}^{6}}{3}\right)\right]_{y_{1}=0}^{y_{1}=1} \\
& =0
\end{aligned}
$$




$$
\begin{aligned}
& B_{02,13}=-\int_{\mathrm{y}_{1}=0}^{\mathrm{y}_{1}=1} \int_{I=0}^{I_{\max }}\left(\frac{\partial \Delta f(\phi)}{\partial b_{02}^{\mathrm{t}}}\right)\left(\frac{\partial \Delta f(\phi)}{\partial b_{13}}\right) \mathrm{d} I \mathrm{~d} y_{1} \\
& =\int_{\mathrm{y}_{1}=0}^{\mathrm{y}_{1}=1 \int_{I=0} \int_{\max }}\left(-y_{1}{ }^{2}+4 y_{1}{ }^{3}-5 \mathrm{y}_{1}{ }^{4}+2 \mathrm{y}_{1}{ }^{5}\right) I^{5} \mathrm{~d} I \mathrm{~d} y \\
& \left.=\left(\frac{I_{\max }^{6}}{6}\right)\left(-\frac{y_{1}^{3}}{3}+y_{1}^{4}-y_{1}^{5}+\frac{y_{1}^{6}}{3}\right)\right]_{y_{1}=0}^{y_{1}=1} \\
& =0 \\
& B_{02,23}=-\int_{\mathrm{y}_{1}=0}^{\mathrm{y}_{1}=1} \int_{I=0}^{I_{\max }}\left(\frac{\partial \Delta f(\phi)}{\partial b_{02}^{\mathrm{t}}}\right)\left(\frac{\partial \Delta f(\phi)}{\partial b_{23}}\right) \mathrm{d} I \mathrm{~d} y_{1} \\
& =\int_{\mathrm{y}_{1}=0}^{\mathrm{y}_{1}=1} \int_{I=0}^{1 I_{\max }}\left(y_{1}{ }^{2}-6 y_{1}{ }^{3}+13 \mathrm{y}_{1}{ }^{4}-12 \mathrm{y}_{1}{ }^{5}+4 \mathrm{y}_{1}{ }^{6}\right) I^{5} \mathrm{~d} I \mathrm{~d} y \\
& \left.=\left(\frac{I_{\max }{ }^{6}}{6}\right)\left(\frac{y_{1}^{3}}{3}-\frac{3 y_{1}^{4}}{2}+\frac{13 y_{1}^{5}}{5}-2 y_{1}{ }^{6}+\frac{4 \mathrm{y}_{1}^{7}}{7}\right)\right]_{y_{1}=0}^{y_{1}=1} \\
& =\left(\frac{I_{\max }^{6}}{1260}\right) \\
& B_{03,01}=-\int_{\mathrm{y}_{1}=0}^{\mathrm{y}_{1}=1} \int_{I=0}^{I_{\max }}\left(\frac{\partial \Delta f(\phi)}{\partial b_{03}^{\mathrm{t}}}\right)\left(\frac{\partial \Delta f(\phi)}{\partial b_{01}}\right) \mathrm{d} I \mathrm{~d} y_{1} \\
& =\int_{\mathrm{y}_{1}=0}^{\mathrm{y}_{1}=1} \int_{I=0}^{I_{\max }}\left(y_{1}^{2}-2 y_{1}^{3}+\mathrm{y}_{1}^{4}\right) I^{4} \mathrm{~d} I \mathrm{~d} y \\
& \left.=\left(\frac{I_{\max }^{5}}{5}\right)\left(\frac{y_{1}^{3}}{3}-\frac{y_{1}^{4}}{2}+\frac{y_{1}^{5}}{5}\right)\right]_{y_{1}=0}^{y_{1}=1} \\
& =\left(\frac{I_{\max }^{5}}{150}\right) \\
& =B_{01,03}
\end{aligned}
$$




$$
\begin{aligned}
& B_{03,02}=-\int_{\mathrm{y}_{1}=0}^{\mathrm{y}_{1}=1} \int_{I=0}^{I_{\max }}\left(\frac{\partial \Delta f(\phi)}{\partial b_{03}^{\mathrm{t}}}\right)\left(\frac{\partial \Delta f(\phi)}{\partial b_{02}}\right) \mathrm{d} I \mathrm{~d} y_{1} \\
& =\int_{\mathrm{y}_{1}=0}^{\mathrm{y}_{1}=1} \int_{I=0}^{I_{\max }}\left(y_{1}^{2}-2 y_{1}^{3}+\mathrm{y}_{1}^{4}\right) I^{5} \mathrm{~d} I \mathrm{~d} y \\
& \left.=\left(\frac{I_{\max }^{6}}{6}\right)\left(\frac{y_{1}^{3}}{3}-\frac{y_{1}^{4}}{2}+\frac{y_{1}^{5}}{5}\right)\right]_{y_{1}=0}^{y_{1}=1} \\
& =\left(\frac{I_{\max }{ }^{6}}{180}\right) \\
& =B_{02,03} \\
& B_{03,12}=-\int_{\mathrm{y}_{1}=0}^{\mathrm{y}_{1}=1} \int_{I=0}^{I_{\max }}\left(\frac{\partial \Delta f(\phi)}{\partial b_{03}^{\mathrm{t}}}\right)\left(\frac{\partial \Delta f(\phi)}{\partial b_{12}}\right) \mathrm{d} I \mathrm{~d} y_{1} \\
& =\int_{\mathrm{y}_{1}=0}^{\mathrm{y}_{1}=1} \int_{I=0}^{I_{\max }}\left(-y_{1}{ }^{2}+4 y_{1}{ }^{3}-5 \mathrm{y}_{1}{ }^{4}+2 \mathrm{y}_{1}{ }^{5}\right) I^{5} \mathrm{~d} I \mathrm{~d} y \\
& \left.=\left(\frac{I_{\max }{ }^{6}}{6}\right)\left(-\frac{y_{1}^{3}}{3}+y_{1}{ }^{4}-y_{1}{ }^{5}+\frac{y_{1}^{6}}{3}\right)\right]_{y_{1}=0}^{y_{1}=1} \\
& =0 \\
& B_{03,13}=-\int_{\mathrm{y}_{1}=0}^{\mathrm{y}_{1}=1} \int_{I=0}^{I_{\max }}\left(\frac{\partial \Delta f(\phi)}{\partial b_{03}^{\mathrm{t}}}\right)\left(\frac{\partial \Delta f(\phi)}{\partial b_{13}}\right) \mathrm{d} I \mathrm{~d} y_{1} \\
& =\int_{\mathrm{y}_{1}=0}^{\mathrm{y}_{1}=1} \int_{I=0}^{I_{\max }}\left(-y_{1}{ }^{2}+4 y_{1}{ }^{3}-5 \mathrm{y}_{1}{ }^{4}+2 \mathrm{y}_{1}{ }^{5}\right) I^{6} \mathrm{~d} I \mathrm{~d} y \\
& \left.=\left(\frac{I_{\max }{ }^{7}}{7}\right)\left(-\frac{y_{1}^{3}}{3}+y_{1}{ }^{4}-y_{1}{ }^{5}+\frac{y_{1}^{6}}{3}\right)\right]_{y_{1}=0}^{y_{1}=1} \\
& =0 \\
& B_{03,23}=-\int_{\mathrm{y}_{1}=0}^{\mathrm{y}_{1}=1} \int_{I=0}^{I_{\max }}\left(\frac{\partial \Delta f(\phi)}{\partial b_{03}^{\mathrm{t}}}\right)\left(\frac{\partial \Delta f(\phi)}{\partial b_{23}}\right) \mathrm{d} I \mathrm{~d} y_{1} \\
& =\int_{\mathrm{y}_{1}=0}^{\mathrm{y}_{1}=1} \int_{I=0}^{I_{\max }}\left(y_{1}{ }^{2}-6 y_{1}{ }^{3}+13 \mathrm{y}_{1}{ }^{4}-12 \mathrm{y}_{1}{ }^{5}+4 \mathrm{y}_{1}{ }^{6}\right) I^{6} \mathrm{~d} I \mathrm{~d} y \\
& \left.=\left(\frac{I_{\max }}{7}\right)\left(\frac{y_{1}^{3}}{3}-\frac{3 y_{1}{ }^{4}}{2}+\frac{13 y_{1}{ }^{5}}{5}-2 y_{1}{ }^{6}+\frac{4 y_{1}^{7}}{7}\right)\right]_{y_{1}=0}^{y_{1}=1} \\
& =\left(\frac{I_{\max }^{7}}{1470}\right)
\end{aligned}
$$




$$
\begin{aligned}
& B_{12,01}=-\int_{\mathrm{y}_{1}=0}^{\mathrm{y}_{1}=1} \int_{I=0}^{I_{\max }}\left(\frac{\partial \Delta f(\phi)}{\partial b_{12}^{\mathrm{t}}}\right)\left(\frac{\partial \Delta f(\phi)}{\partial b_{01}}\right) \mathrm{d} I \mathrm{~d} y_{1} \\
& =B_{01,12} \\
& =0 \\
& B_{12,02}=-\int_{\mathrm{y}_{1}=0}^{\mathrm{y}_{1}=1} \int_{I=0}^{I_{\max }}\left(\frac{\partial \Delta f(\phi)}{\partial b_{12}^{\mathrm{t}}}\right)\left(\frac{\partial \Delta f(\phi)}{\partial b_{02}}\right) \mathrm{d} I \mathrm{~d} y_{1} \\
& =B_{02,12} \\
& =0 \\
& B_{12,03}=\int_{\mathrm{y}_{1}=0}^{\mathrm{y}_{1}=1 I_{\max }} \int_{I=0}\left(\frac{\partial \Delta f(\phi)}{\partial b_{12}^{\mathrm{t}}}\right)\left(\frac{\partial \Delta f(\phi)}{\partial b_{03}}\right) \mathrm{d} I \mathrm{~d} y_{1} \\
& =B_{03,12} \\
& =0 \\
& B_{12,13}=-\int_{\mathrm{y}_{1}=0}^{\mathrm{y}_{1}=1} \int_{I=0}^{I_{\max }}\left(\frac{\partial \Delta f(\phi)}{\partial b_{12}^{\mathrm{t}}}\right)\left(\frac{\partial \Delta f(\phi)}{\partial b_{13}}\right) \mathrm{d} I \mathrm{~d} y_{1} \\
& =\int_{\mathrm{y}_{1}=0}^{\mathrm{y}_{1}=1} \int_{I=0}^{I_{\max }}\left(-y_{1}+3 y_{1}{ }^{2}-2 y_{1}{ }^{3}\right)^{2} I^{5} \mathrm{~d} I \mathrm{~d} y \\
& \left.=\left(\frac{I_{\max }{ }^{6}}{6}\right)\left(\frac{y_{1}^{3}}{3}-\frac{3 y_{1}{ }^{4}}{2}+\frac{13 y_{1}^{5}}{5}-2 y_{1}{ }^{6}+\frac{4 y_{1}^{7}}{7}\right)\right]_{y_{1}=0}^{y_{1}=1} \\
& =\left(\frac{I_{\max }^{6}}{1260}\right) \\
& B_{12,23}=-\int_{\mathrm{y}_{1}=0}^{\mathrm{y}_{1}=1 \int_{I=0} \int_{\max }}\left(\frac{\partial \Delta f(\phi)}{\partial b_{12}^{\mathrm{t}}}\right)\left(\frac{\partial \Delta f(\phi)}{\partial b_{23}}\right) \mathrm{d} I \mathrm{~d} y_{1} \\
& =\int_{\mathrm{y}_{1}=0}^{\mathrm{y}_{1}=1 I_{I=0}} \int_{\max }\left(-y_{1}{ }^{2}+8 y_{1}{ }^{3}-25 \mathrm{y}_{1}{ }^{4}+38 \mathrm{y}_{1}{ }^{5}-28 \mathrm{y}_{1}{ }^{6}+8 \mathrm{y}_{1}{ }^{7}\right) I^{5} \mathrm{~d} I \mathrm{~d} y \\
& \left.=\left(\frac{I_{\max }{ }^{6}}{6}\right)\left(-\frac{y_{1}^{3}}{3}+2 y_{1}{ }^{4}-5 y_{1}{ }^{5}+\frac{19 y_{1}{ }^{6}}{3}-4 \mathrm{y}_{1}{ }^{7}+\mathrm{y}_{1}{ }^{8}\right)\right]_{y_{1}=0}^{y_{1}=1} \\
& =0
\end{aligned}
$$




$$
\begin{aligned}
& B_{13,01}=\int_{\mathrm{y}_{1}=0}^{\mathrm{y}_{1}=1 I_{I=0}} \int_{\max }\left(\frac{\partial \Delta f(\phi)}{\partial b_{13}^{\mathrm{t}}}\right)\left(\frac{\partial \Delta f(\phi)}{\partial b_{01}}\right) \mathrm{d} I \mathrm{~d} y_{1} \\
& =B_{01,13} \\
& =0 \\
& B_{13,02}=-\int_{\mathrm{y}_{1}=0}^{\mathrm{y}_{1}=1} \int_{I=0}^{I_{\max }}\left(\frac{\partial \Delta f(\phi)}{\partial b_{13}^{\mathrm{t}}}\right)\left(\frac{\partial \Delta f(\phi)}{\partial b_{02}}\right) \mathrm{d} I \mathrm{~d} y_{1} \\
& =B_{02,13} \\
& =0 \\
& B_{13,03}=-\int_{\mathrm{y}_{1}=0}^{\mathrm{y}_{1}=1} \int_{I=0}^{I_{\max }}\left(\frac{\partial \Delta f(\phi)}{\partial b_{13}^{\mathrm{t}}}\right)\left(\frac{\partial \Delta f(\phi)}{\partial b_{03}}\right) \mathrm{d} I \mathrm{~d} y_{1} \\
& =B_{03,13} \\
& =0 \\
& B_{13,12}=-\int_{\mathrm{y}_{1}=0}^{\mathrm{y}_{1}=1} \int_{I=0}^{I_{\max }}\left(\frac{\partial \Delta f(\phi)}{\partial b_{13}^{\mathrm{t}}}\right)\left(\frac{\partial \Delta f(\phi)}{\partial b_{12}}\right) \mathrm{d} I \mathrm{~d} y_{1} \\
& =B_{12,13} \\
& =\left(\frac{I_{\max }^{6}}{1260}\right) \\
& B_{13,23}=-\int_{\mathrm{y}_{1}=0}^{\mathrm{y}_{1}=1 I_{I=0} \int_{\max }}\left(\frac{\partial \Delta f(\phi)}{\partial b_{13}^{\mathrm{t}}}\right)\left(\frac{\partial \Delta f(\phi)}{\partial b_{23}}\right) \mathrm{d} I \mathrm{~d} y_{1} \\
& =\int_{\mathrm{y}_{1}=0}^{\mathrm{y}_{1}=1 I_{I=0}^{I_{\max }}}\left(-y_{1}{ }^{2}+8 y_{1}{ }^{3}-25 \mathrm{y}_{1}{ }^{4}+38 \mathrm{y}_{1}{ }^{5}-28 \mathrm{y}_{1}{ }^{6}+8 \mathrm{y}_{1}{ }^{7}\right) I^{6} \mathrm{~d} I \mathrm{~d} y \\
& \left.=\left(\frac{I_{\max }}{7}\right)\left(-\frac{y_{1}^{3}}{3}+2 y_{1}{ }^{3}-5 y_{1}{ }^{5}+\frac{19 y_{1}{ }^{6}}{3}-4 \mathrm{y}_{1}{ }^{7}+\mathrm{y}_{1}{ }^{8}\right)\right]_{y_{1}=0}^{y_{1}=1} \\
& =0
\end{aligned}
$$




$$
\begin{aligned}
& B_{23,01}=-\int_{\mathrm{y}_{1}=0}^{\mathrm{y}_{1}=1} \int_{I=0}^{I_{\max }}\left(\frac{\partial \Delta f(\phi)}{\partial b_{23}^{\mathrm{t}}}\right)\left(\frac{\partial \Delta f(\phi)}{\partial b_{01}}\right) \mathrm{d} I \mathrm{~d} y_{1} \\
& =B_{01,23} \\
& =\left(\frac{I_{\max }^{5}}{1050}\right) \\
& B_{23,02}=-\int_{\mathrm{y}_{1}=0}^{\mathrm{y}_{1}=1} \int_{I=0}^{I_{\max }}\left(\frac{\partial \Delta f(\phi)}{\partial b_{23}^{\mathrm{t}}}\right)\left(\frac{\partial \Delta f(\phi)}{\partial b_{02}}\right) \mathrm{d} I \mathrm{~d} y_{1} \\
& =B_{02,23} \\
& =\left(\frac{I_{\max }{ }^{6}}{1260}\right) \\
& B_{23,03}=-\int_{\mathrm{y}_{1}=0}^{\mathrm{y}_{1}=1} \int_{I=0}^{I_{\max }}\left(\frac{\partial \Delta f(\phi)}{\partial b_{23}^{\mathrm{t}}}\right)\left(\frac{\partial \Delta f(\phi)}{\partial b_{03}}\right) \mathrm{d} I \mathrm{~d} y_{1} \\
& =B_{03,23} \\
& =\left(\frac{I_{\max }{ }^{7}}{1470}\right) \\
& B_{23,12}=-\int_{\mathrm{y}_{1}=0}^{\mathrm{y}_{1}=1} \int_{I=0}^{I_{\max }}\left(\frac{\partial \Delta f(\phi)}{\partial b_{23}^{\mathrm{t}}}\right)\left(\frac{\partial \Delta f(\phi)}{\partial b_{12}}\right) \mathrm{d} I \mathrm{~d} y_{1} \\
& =B_{12,23} \\
& =0 \\
& B_{23,13}=-\int_{\mathrm{y}_{1}=0}^{\mathrm{y}_{1}=1} \int_{I=0}^{I_{\max }}\left(\frac{\partial \Delta f(\phi)}{\partial b_{23}^{\mathrm{t}}}\right)\left(\frac{\partial \Delta f(\phi)}{\partial b_{13}}\right) \mathrm{d} I \mathrm{~d} y_{1} \\
& =B_{13,23} \\
& =0
\end{aligned}
$$


Appendix C Example for the matrices $B_{j k, l m}$ and $A_{j k, l m}$, and the right-hand-side vector $c_{j k}$ for the specific case of the six-parameter source model and a truncated parameter set model that only has the four model parameters $b_{01}^{\mathrm{t}}, b_{02}^{\mathrm{t}}, b_{12}^{\mathrm{t}}$, and $b_{23}^{\mathrm{t}}$

Here we give a specific example of the matrices and vector defined by Eq. 24. See Appendix B for the evaluation of the individual matrix elements. The $B_{j k, l m}$ matrix for the six-parameter source model is given by

$$
B_{j k, l m}=\left[\begin{array}{cccccc}
\frac{I_{\max }^{3}}{90} & \frac{I_{\max }^{4}}{120} & \frac{I_{\max }^{5}}{150} & 0 & 0 & \frac{I_{\max }^{5}}{1050} \\
\frac{I_{\max }^{4}}{120} & \frac{I_{\max }^{5}}{150} & \frac{I_{\max }^{6}}{180} & 0 & 0 & \frac{I_{\max }^{6}}{1260} \\
\frac{I_{\max }^{5}}{150} & \frac{I_{\max }^{6}}{180} & \frac{I_{\max }^{7}}{210} & 0 & 0 & \frac{I_{\max }^{7}}{1470} \\
0 & 0 & 0 & \frac{I_{\max }^{5}}{1050} & \frac{I_{\max }^{6}}{1260} & 0 \\
0 & 0 & 0 & \frac{I_{\max }^{6}}{1260} & \frac{I_{\max }^{7}}{1470} & 0 \\
\frac{I_{\max }^{5}}{1050} & \frac{I_{\max }^{6}}{1260} & \frac{I_{\max }^{7}}{1470} & 0 & 0 & \frac{I_{\max }^{7}}{4410}
\end{array}\right]
$$

The $A_{j k, l m}$ matrix for the four-parameter truncated parameter model is similarly given by

$$
A_{j k, l m}=\left[\begin{array}{cccccc}
\frac{I_{\max }^{3}}{90} & \frac{I_{\max }^{4}}{120} & 0 & 0 & 0 & \frac{I_{\max }^{5}}{1050} \\
\frac{I_{\max }^{4}}{120} & \frac{I_{\max }^{5}}{150} & 0 & 0 & 0 & \frac{I_{\max }^{6}}{1260} \\
0 & 0 & 1 & 0 & 0 & 0 \\
0 & 0 & 0 & \frac{I_{\max }^{7}}{1050} & 0 & 0 \\
0 & 0 & 0 & 0 & 1 & 0 \\
\frac{I_{\max }^{5}}{1050} & \frac{I_{\max }^{6}}{1260} & 0 & 0 & 0 & \frac{I_{\max }^{7}}{4410}
\end{array}\right]
$$

and the right-hand-side vector $c_{j k}$ by 


$$
c_{j k}=\left[\begin{array}{c}
B_{01,01} b_{01}+B_{01,02} b_{02}+B_{01,03} b_{03}+B_{01,12} b_{12}+B_{01,13} b_{13}+B_{01,23} b_{23} \\
B_{02,01} b_{01}+B_{02,02} b_{02}+B_{02,03} b_{03}+B_{02,12} b_{12}+B_{02,13} b_{13}+B_{02,23} b_{23} \\
0 \\
B_{12,01} b_{01}+B_{12,02} b_{02}+B_{12,03} b_{03}+B_{12,12} b_{12}+B_{12,13} b_{13}+B_{12,23} b_{23} \\
0 \\
B_{23,01} b_{01}+B_{23,02} b_{02}+B_{23,03} b_{03}+B_{23,12} b_{12}+B_{23,13} b_{13}+B_{23,23} b_{23}
\end{array}\right]
$$

